NBER WORKING PAPER SERIES

\title{
ELICITING PEOPLE'S FIRST-ORDER CONCERNS: TEXT ANALYSIS OF OPEN-ENDED SURVEY QUESTIONS
}

\author{
Beatrice Ferrario \\ Stefanie Stantcheva \\ Working Paper 29686 \\ http://www.nber.org/papers/w29686 \\ NATIONAL BUREAU OF ECONOMIC RESEARCH \\ 1050 Massachusetts Avenue \\ Cambridge, MA 02138 \\ January 2022
}

We thank Chantal Pezold and Martha Fiehn for excellent research assistance. The views expressed herein are those of the authors and do not necessarily reflect the views of the National Bureau of Economic Research.

NBER working papers are circulated for discussion and comment purposes. They have not been peer-reviewed or been subject to the review by the NBER Board of Directors that accompanies official NBER publications.

(C) 2022 by Beatrice Ferrario and Stefanie Stantcheva. All rights reserved. Short sections of text, not to exceed two paragraphs, may be quoted without explicit permission provided that full credit, including $\odot$ notice, is given to the source. 
Eliciting People's First-Order Concerns: Text Analysis of Open-Ended Survey Questions Beatrice Ferrario and Stefanie Stantcheva

NBER Working Paper No. 29686

January 2022

JEL No. D72,D91,H1,H2

\begin{abstract}
$\underline{\text { ABSTRACT }}$
This paper illustrates the design and use of open-ended survey questions as a way of eliciting people's first-order concerns on policies. Multiple choice questions are the backbone of most surveys, but they may prime respondents to select answer options that they would not naturally have thought about, and they may omit relevant options. Open-ended questions that do not constrain respondents with specific answer choices are a valuable tool for eliciting first-order thinking. We discuss three text analysis methods to analyze open-ended questions' answers. To illustrate how to apply these methods, we provide evidence from large-scale surveys on income and estate taxation. We show the that key concerns relate mostly to distribution issues, fairness, and government, rather than to efficiency concerns. There are large partisan gaps in the first-order concerns on policies.
\end{abstract}

\author{
Beatrice Ferrario \\ Harvard University \\ 1805 Cambridge Street \\ Cambridge, MA 02138 \\ bv.ferrario@gmail.com \\ Stefanie Stantcheva \\ Department of Economics \\ Littauer Center 232 \\ Harvard University \\ Cambridge, MA 02138 \\ and NBER \\ sstantcheva@fas.harvard.edu
}




\title{
Eliciting People's First-Order Concerns: Text Analysis of Open-Ended Survey Questions
}

\author{
By Beatrice Ferrario and Stefanie Stantcheva*
}

Surveys are a key tool for understanding people's views on public policies. They let us slip into people's minds and reveal otherwise invisible things such as attitudes, perceptions, reasonings, and beliefs. They can shed light on how people reason about important policies that shape their daily lives, such as health care, taxation, and trade policy. What efficiency and distributional impacts do people have in mind when thinking about these policies? What are their perceived goals and social objectives?

To some extent, we can learn about support for some policies by observing citizens' political behaviors. Yet, we lack data on their more detailed policy preferences since voting rarely happens on specific and separate issues. Furthermore, it is difficult to infer the reasoning underlying people's policy views using observational data. Survey methods are thus an invaluable complement to our other research methods.

The backbone of surveys often consists of closed-ended questions that provide a fixed set of answer options. The advantages of these questions are that answer options are standardized and streamlined across respondents and they easily lend themselves to quantitative analysis. However, in some settings, we may prime respondents to think about (and, subsequently, perhaps select) answer options that they would otherwise not have thought about. Conversely, we may omit relevant options that we do not know about. In open-ended questions, respondents are not offered answer options, but rather, an empty text entry field in

\footnotetext{
* Ferrario: Harvard University, 1805 Cambridge Street, Cambridge, MA 02138 (e-mail: beatrice_ferrario@g.harvard.edu); Stantcheva (corresponding author): Harvard University, CEPR, and NBER, 1805 Cambridge Street, Cambridge, MA 02138 (e-mail: sstantcheva@fas.harvard.edu). We thank Chantal Pezold and Martha Fiehn for exceptional research assistance.
}

which they can write freely. Open-ended survey questions can therefore circumvent some of the above-mentioned issues. By being less guided, they may teach us things that we may otherwise have missed and that we may not be used to thinking about as economists. The answers to these openended questions can be analyzed using text analysis methods to shed light on the firstorder considerations that come to people's minds without constraining them to think about a limited set of answer options.

This paper illustrates the design and use of open-ended survey questions, focusing on the topics of income and estate taxation.

An abundant literature leverages survey data to explore people's perceptions and preferences about tax policy and redistribution (Gimpelson and Treisman, 2018; Alesina, Stantcheva and Teso, 2018; Stantcheva, 2021; Fisman et al., 2020; Cruces, Perez-Truglia and Tetaz, 2013; Karadja, Mollerstrom and Seim, 2017; Roth and Wohlfart, 2018; Hvidberg, Kreiner and Stantcheva, 2020). Perceptions (and misperceptions) of tax rates are documented in De Bartolome (1995), Gideon (2017), Ballard and Gupta (2018), Rees-Jones and Taubinsky (2019), Chetty, Friedman and Saez (2013), Feldman, Katuščák and Kawano (2016), and Stantcheva (2021).

Text analysis methods of non-survey data, such as online media and newspaper coverage, have been applied in finance (Antweiler and Frank, 2004), macroeconomics (Baker, Bloom and Davis, 2016), and political economy (Groseclose and $\mathrm{Mi}$ lyo, 2005; Gentzkow and Shapiro, 2010; Tesei, Durante and Pinotti, 2018; Gentzkow, Kelly and Taddy, 2019). Our goal is to apply text analysis methods to data derived from answers to open-ended survey questions. A few papers in political sci- 
ence (Roberts et al., 2014; Brugidou, 2003) leverage open-ended survey questions, and the practice is also starting to spread to economics (Stantcheva, 2020; Houde and Wekhof, 2021).

The data for this paper comes from two surveys on income and estate taxes, conducted in 2019 on 5140 U.S. residents aged 18 to 70 . The sample is representative of the U.S. population along the dimension of gender, age, income, political affiliation, and employment (see Appendix OA-1). Section I presents the application of text analysis to open-ended survey questions. Section II summarizes key results about people's views on income and estate taxation.

\section{Using Open-Ended Survey Questions}

\section{A. What do Open-ended Questions Measure?}

Open-ended questions can go from broad to narrow. Broader open-ended questions are useful to elicit first-order, intrinsic concerns that people have before they are prompted to think of a particular policy aspect with more directed questions. Thus, it makes sense to start by asking people big picture questions such as the "main considerations" that come to their minds when they think about an issue (e.g., the income or estate tax). In our application, we then narrow the focus by asking people what a "good" tax system means to them and what its goals should be, as well as what their main perceived shortcomings of the current U.S. tax system are. Finally, one can ask targeted questions, such as about the effects on the U.S. economy and on different groups of people if the policy were changed (e.g., "What would be the effects on the economy if taxes on high earners were raised?"). ${ }^{1}$ Ideally, open-ended questions should be complemented with closedended questions for cross-validation.

It is useful to think about what the answers to open-ended questions capture. The answers of respondents who have

\footnotetext{
${ }^{1}$ Appendix Section OA-2 provides all the questions asked.
}

not previously thought carefully about the topic may be "gut reactions." These reactions are informative, as they reflect what a respondent thinks and will keep thinking, absent more learning or targeted reflection. The answers of respondents who have already thought about the topic previously or take time to think about it during the survey before answering may reflect more profound views. ${ }^{2}$ Either way, answers to open-ended questions capture the firstorder considerations that matter to people and the aspects of an issue that are top of mind for them.

\section{B. Text Analysis Methods for Open-Ended Questions}

\section{DATA PRE-PROCESSING}

To prepare the data for text analysis, we first parse the answers to reduce the number of distinct text elements. We remove punctuation, excess spaces, numbers, misspelled words, and so-called "stop words," which are common words that carry no intrinsic meaning such as "and" or "the." The remaining words in each answer are then lemmatized to group all inflected forms of a word. ${ }^{3}$ Words appearing in the question itself or that occur generically in answers can also be removed (e.g., "think," "believe," and "should"). Appendix OA-4 describes the data pre-processing in detail. We now briefly present three text analysis methods, with more details in Appendix OA-5.

\section{Word Clouds}

For each of the methods presented, a decision has to be made on the basic unit of analysis, i.e., the size of word groups that will be considered as a set. "N-grams" are groups of $n$ words. In word clouds, the font size for each n-gram is proportional to its frequency. Word clouds are best used as a first step in visualizing the data and for scanning answers quickly. Their weakness

\footnotetext{
${ }^{2}$ The time spent on each question can be measured and thus, it is possible to distinguish between these two types of responses.

${ }^{3}$ For instance, "policies" becomes "policy," "were" becomes "be."
} 
is that they do not account for synonyms. Hence, topics for which there are many possible words to express the same thought may be artificially diluted, while niche topics that feature clear buzzwords may be inflated in importance.

\section{KEYNESS ANALYSIS}

Keyness analysis is based on a relative frequency analysis that compares the use of n-grams between two groups (a reference and a target/study group). The keyness scores of an n-gram are based on the $\chi^{2}$ test statistic for the null hypothesis that the propensity to use the n-gram is the same for the reference and target groups. In a nutshell, the keyness score of a term measures how characteristic this term is of the reference group. Words that are common, but used relatively equally by the two groups do not have a high keyness score.

\section{TOPIC ANALysis}

The topic analysis is based on a keywords-count model. Topics are defined by sets of keywords. To extract the topics and associated keywords, approaches range from manual to semi-supervised or unsupervised (see Appendix OA-5 for a summary of some key methods). Many of these methods are developed for longer text and are not that well-suited for survey answers which are shorter in length. In practice, given the manageable sample sizes, a more guided approach does better. We recommend extracting the "document-term matrix" (matrix of frequencies of terms in each answer), plotting the distributions of words, and checking many sample answers to better understand how words are used by respondents. Oftentimes, themes and commonly used words appear quite clearly from the frequency distributions. It is, however, important to do sensitivity checks on the topics delineated and on the keywords included. Among other decisions that need to be made (and which warrant sensitivity analysis) are whether to count a topic that is mentioned multiple times by a respondent only once or not, and whether to filter out differences in answer lengths across groups by computing topic distributions within groups.

\section{Application: How Do People Think About Taxes?}

To apply these methods to how people think about income and estate taxation, we focus on answers to the broad question "What are your main considerations?" when thinking about income or estate taxes, respectively. The other openended questions are analyzed in Appendix OA-8. Figure 1 shows the word clouds derived from the responses. For the income tax, respondents express disagreement with the current levels of taxes and views on the direction in which to change them ("lower

(a) Income Tax

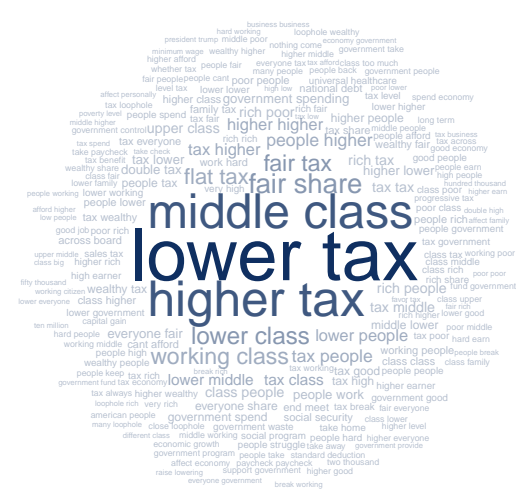

(b) Estate Tax

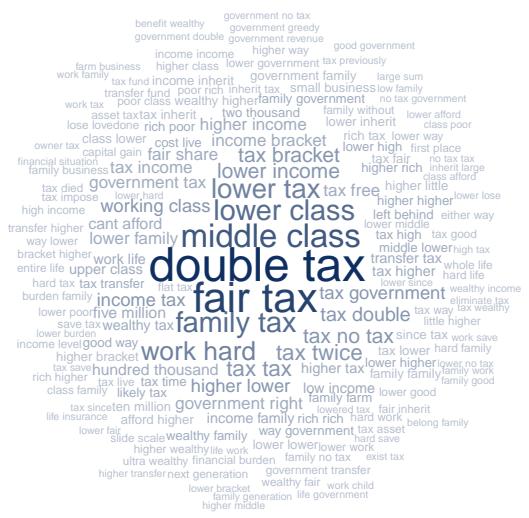

Figure 1. : Main Considerations about Income and Estate Taxes

Note: Word clouds based answers to open-ended question about respondents' main considerations about income and estate taxes. 
tax" or "higher tax," depending on the groups they refer to) and concern about the impacts on the "middle class." For the estate tax, respondents' first-order reaction centers around "double taxation" and the fairness of the estate tax, followed closely by concerns about the "middle class" and "family."

\section{A. Key topics mentioned}

Figure 2 shows the distribution of topics in respondents' answers by political affiliation. For the income tax, there are eight distinct topics: Distribution, Fairness, Government Spending, Social Insurance, Efficiency, Loopholes, Flat Tax, Public Goods, and Don't Know (the labels are chosen by us and need not be words used by respondents). For instance, the Distribution topic contains keywords such as "middle class," "low income," "millionaire." The Fairness issue contains the words "fair" and "unfair." Public Goods captures "infrastructure," "education," and "health care." Efficiency is represented by words such as "hurt economy," "work less," "competition," and "spend less," among others. The final category is for respondents who express that they do not know enough about the policy to give a meaningful answer. Appendix OA-6 lists the full set of keywords identifying each topic, and example answers are in Appendix OA-7. An answer is counted as mentioning a topic if it contains at least one of the topic keywords. Answers can thus contain multiple topics.

The topics of Distribution and Fairness, as well as Government Spending and Loopholes are most frequently mentioned. The Efficiency topic does not appear to be top of mind for most people. These results echo Stantcheva (2021), which uses a finer decomposition analysis that leverages a series of (non open-ended) survey questions. The paper finds that distributional and fairness considerations dominate efficiency concerns in shaping people's tax policy views. Thus, people's responses to the open-ended questions already provide meaningful insights into what matters to them.

For the estate tax in Panel B, the topics are similar to those from the income

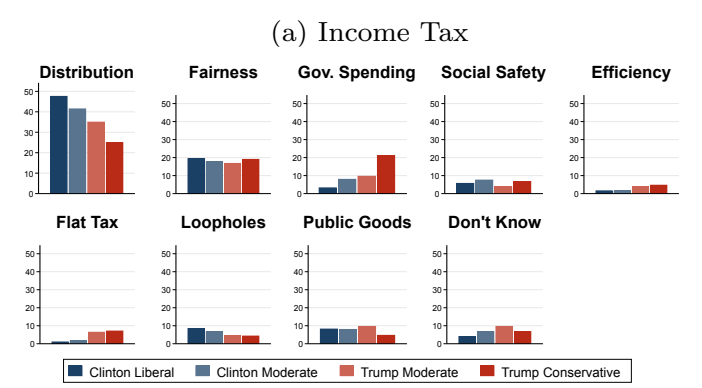

(b) Estate Tax

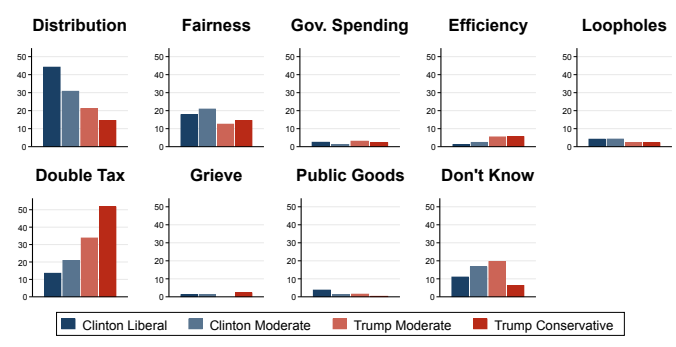

Figure 2. : Main Topics Respondents think About Regarding the Income and Estate Taxes by Political Affiliation

Note: The figure shows distribution of topics mentioned in the answers about main considerations about income and estate taxes. The bars represent the number of times a topic was mentioned out of the total mentions of any topic by political group.

tax survey. Specific to the estate tax is the Double Tax topic, captured by keywords such as "already taxed," "already paid," and "taxed/paid twice" and the Grieve topic, which is captured by terms such as "grieve," "bury," and "funeral." The distribution of topics is again heavily centered around issues of Distribution and Fairness, but Double Tax also carries a lot of weight. Much rarer are mentions of Government Spending, Efficiency, Loopholes, Grieve, and Public Goods. Furthermore, more people express a lack of knowledge about the estate tax than the income tax.

\section{B. Political differences in topics mentioned}

It is useful to plot topic distributions for different groups to see whether first-order concerns are heterogeneous across respondents. Figure 2 does this by political affiliation, while Appendix OA-8 provides cuts by age, income, and education groups. Political leanings are captured by both the vote in 2016 (Clinton vs. Trump) and by a self- 
reported degree of conservatism vs. liberalism (see Appendix OA-3 for details). The four main categories that emerge are: Clinton Liberals, Clinton Moderates, Trump Moderates, and Trump Conservatives.

There are clear political differences in the topics mentioned. Issues related to Distribution are much more prevalent on the left side of the political spectrum than on the right: they represent $50 \%$ of topics mentioned by Clinton Liberals and $25 \%$ by Trump Conservatives. Government spending, on the other hand, is a more pressing concern for respondents on the right, accounting for less than $4 \%$ of topic mentions for Clinton Liberals and $22 \%$ for Trump Conservatives. Efficiency is not frequently mentioned by any political group. Fairness mentions are quite evenly distributed across the political spectrum. However, even though everyone cares about fairness, the meaning of this concept greatly differs across respondents: fairness is in the eye of the beholder. The answers to this broad open-ended question thus prompt us to ask more detailed (openand closed-ended) questions about fairness (Stantcheva, 2021).

Figure 3 shows the keywords that are most specific to Democrats and Republicans. Consistent with the topic distribution, the keywords on the Democrat side center around issues of Distribution ("poor rich," "lower class," "middle class," and "tax wealthy"). Republicans tend to emphasize Government Spending, Government Waste, and the Economic Costs ("people work," "economy spend").

For the estate tax, there are also clear differences in the topics mentioned by political leanings. Distribution issues are most prevalent among Clinton Liberals and diminish rapidly and monotonically towards Trump Conservatives. Conversely, Double Taxation concerns are prevalent among Trump Conservatives, but quite rare among Clinton Liberals. The mentions of Fairness are again evenly distributed across the political spectrum. These patterns are confirmed by the keyness analysis (Panel B of Figure 3).
Figure OA-2 shows the distribution of responses to the question "Who gains if taxes on high earners were increased?" Among Democrats, prevalent answers are "the middle class" and "everybody." Among Republicans, common answers are "nobody" and "government and politicians." This shows that beliefs in "trickle-down" economics are

(a) Income Tax

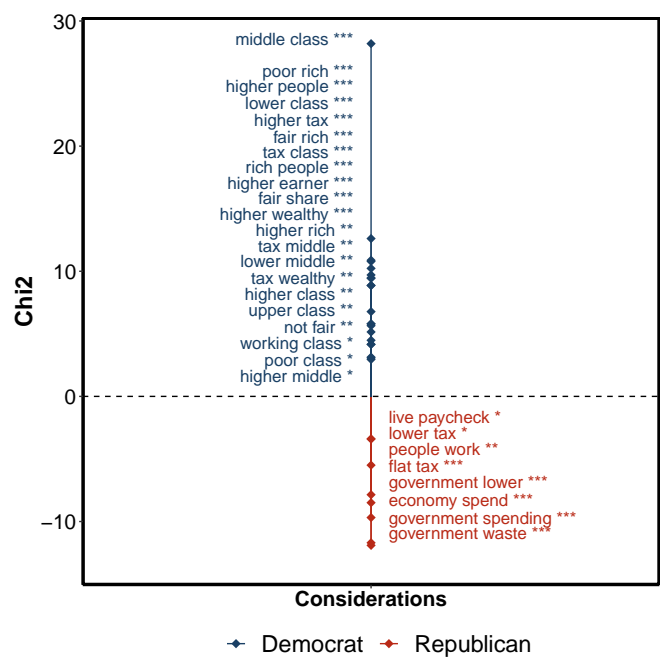

(b) Estate Tax

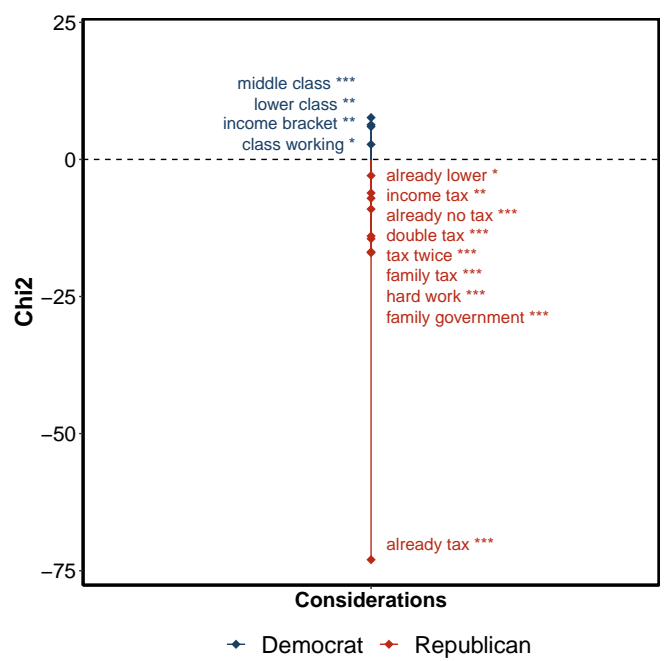

Figure 3. : Keywords Mentioned by Democrats and Republicans Regarding the Income and Estate Taxes

Note: The figure shows keywords among Democrats and Republicans in answers to the question about respondents' main considerations on the income and estate taxes. The score reported for a set of two words is the $\chi^{2}$ - test statistic, testing the null hypothesis that the occurrence of the given keywords is the same among Democrats and Republicans. ${ }^{*} p<0.1,{ }^{* *} p<0.05$ $* * * p<0.01$. See Appendix OA-5.2. 
more prevalent on the right. Figure OA-6 shows similar perceived winners and losers from estate tax increases.

On the perceived shortcomings of the income tax, Figure OA-3 shows that keywords specific to Democrats relate to Loopholes and Tax Breaks for the Rich and Corporations, while for Republicans they center around Government Spending and Work (i.e., that taxes discourage work and that it is unfair to tax hard-working people).

\section{Conclusion}

Open-ended survey questions offer the potential to elicit people's first-order considerations on policy issues. By not constraining respondents to a given set of answer choices, they avoid priming them to think of otherwise non-salient options or omitting relevant options. Open-ended questions can range from broader to more targeted. Leveraging recent advances in text analysis, their answers can be visualized and quantitatively studied to shed light across many areas of economics.

\section{REFERENCES}

Alesina, Alberto, Stefanie Stantcheva, and Edoardo Teso. 2018. "Intergenerational mobility and preferences for redistribution." American Economic Review, 108(2): 521-54.

Antweiler, Werner, and Murray Z. Frank. 2004. "Is All That Talk Just Noise? The Information Content of Internet Stock Message Boards." The Journal of Finance, 59(3): 12591294.

Baker, Scott R, Nicholas Bloom, and Steven J Davis. 2016. "Measuring economic policy uncertainty." The Quarterly Journal of Economics, 131(4): 1593-1636.

Ballard, Charles L, and Sanjay Gupta. 2018. "Perceptions and realities of average tax rates in the federal income tax: evidence from Michigan." National Tax Journal, 71(2): 263-294.

Brugidou, Mathieu. 2003. "Argumentation and Values: an analysis of ordinary political competence via an open-ended question." International Journal of Public Opinion Research, 15(4): 413430.

Chetty, Raj, John N Friedman, and Emmanuel Saez. 2013. "Using Differences in Knowledge across Neighborhoods to Uncover the Impacts of the EITC on Earnings." American Economic Review, 103(7): 2683-2721.

Cruces, Guillermo, Ricardo Perez-Truglia, and Martin Tetaz. 2013. "Biased Perceptions of Income Distribution and Preferences for Redistribution: Evidence from a Survey Experiment." Journal of Public Economics, 98(C): 100112 .
De Bartolome, Charles AM. 1995. "Which tax rate do people use: Average or marginal?" Journal of Public Economics, 56(1): 79-96.

Feldman, Naomi E, Peter Katuščák, and Laura Kawano. 2016. "Taxpayer confusion: Evidence from the child tax credit." American Economic Review, 106(3): 807-35.

Fisman, Raymond, Keith Gladstone, Ilyana Kuziemko, and Suresh Naidu. 2020. "Do americans want to tax wealth? evidence from online surveys." Journal of Public Economics, 188: 104207.

Gentzkow, Matthew, and Jesse M Shapiro. 2010. "What drives media slant? Evidence from US daily newspapers." Econometrica, 78(1): 3571.

Gentzkow, Matthew, Bryan Kelly, and Matt Taddy. 2019. "Text as Data." Journal of Economic Literature, 57(3): 535-74.

Gideon, Michael. 2017. "Do Individuals Perceive Income Tax Rates Correctly?" Public Finance Review, 45(1): 97-117.

Gimpelson, Vladimir, and Daniel Treisman. 2018. "Misperceiving inequality." Economics $\mathcal{E}$ Politics, 30(1): 27-54.

Groseclose, Tim, and Jeffrey Milyo. 2005. "A measure of media bias." The Quarterly Journal of Economics, 120(4): 1191-1237.

Houde, Sébastien, and Tobias Wekhof. 2021. "The narrative of the energy efficiency gap." Economics Working Paper Series, 21.

Hvidberg, Kristoffer, Claus Kreiner, and Stefanie Stantcheva. 2020. "Social Position and Fairness Views." NBER Working Paper 28099.

Karadja, Mounir, Johanna Mollerstrom, and David Seim. 2017. "Richer (and Holier) than Thou? The Effect of Relative Income Improvements on Demand for Redistribution." Review of Economics and Statistics, 99(2): 201-212.

Rees-Jones, Alex, and Dmitry Taubinsky. 2019. "Measuring "Schmeduling"." The Review of Economic Studies, 87(5): 2399-2438.

Roberts, Margaret E, Brandon M Stewart, Dustin Tingley, Christopher Lucas, Jetson Leder-Luis, Shana Kushner Gadarian, Bethany Albertson, and David G Rand. 2014. "Structural topic models for open-ended survey responses." American Journal of Political Science, 58(4): 1064-1082.

Roth, Christopher, and Johannes Wohlfart. 2018. "Experienced Inequality and Preferences for Redistribution." Journal of Public Economics, 167: 251-262.

Stantcheva, Stefanie. 2020. "Understanding Economic Policies: What Do People Know and How Can They Learn?" Harvard University Working Paper.

Stantcheva, Stefanie. 2021. "Understanding tax policy: How do people reason?" The Quarterly Journal of Economics, 136(4): 2309-2369.

Tesei, A, R Durante, and P Pinotti. 2018. "The Political Legacy of Entertainment TV." American Economic Review. 


\title{
ONLINE APPENDIX
}

\section{for "Eliciting People's First-Order Concerns: Text Analysis of Open-Ended Survey Questions"}

\author{
by Beatrice Ferrario and Stefanie Stantcheva
}

\section{Contents}

OA-1 Representativeness of the Sample . . . . . . . . . . . . . . . OA-2

OA-2 Open-ended Questions Wording . . . . . . . . . . . . . . . OA-3

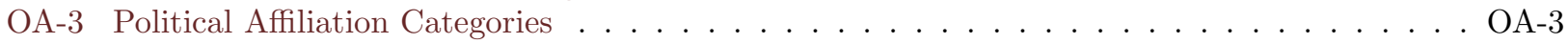

OA-4 Preprocessing Steps . . . . . . . . . . . . . . . . . . . . OA-5

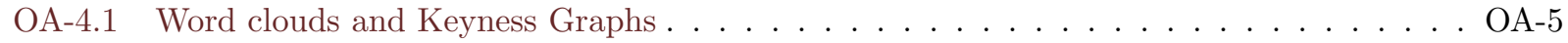

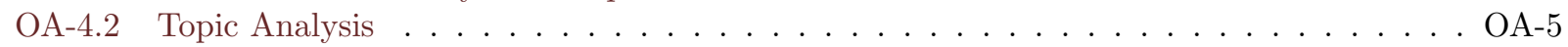

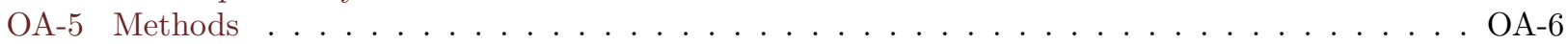

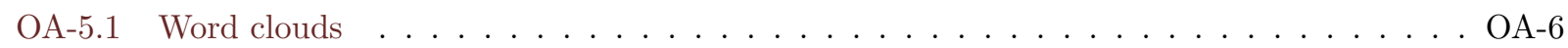

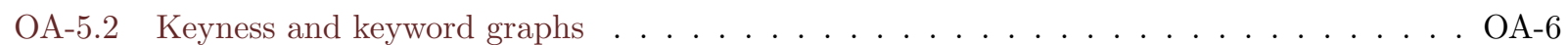

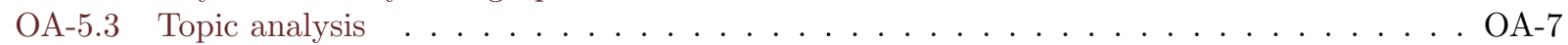

OA-6 Topic Keywords . . . . . . . . . . . . . . . . . . . . . OA-8

OA-7 Sample of Answers to the Open-ended Question "What are your Main Considerations about the Policy?" . . . . . . . . . . . . . . . . . . . . . . . OA-9

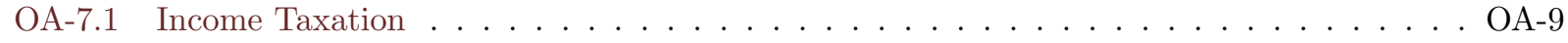

OA-7.2 Estate $\operatorname{Tax} \ldots \ldots \ldots \ldots \ldots \ldots \ldots \ldots \ldots \ldots$

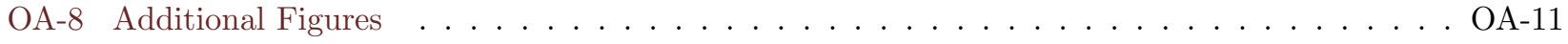

\section{List of Figures}

OA-1 Word clouds for the Income Tax $\ldots \ldots \ldots \ldots \ldots \ldots$. . . . . . . . . . . . . . . .

OA-2 Distributional effects of Income Tax Increase: Who Gains if Taxes on High Earners were to be Increased $\quad \ldots \ldots \ldots$. . . . . . . . . . . . . . . . . . . OA-13

OA-3 Keywords of Income Taxation by Groups ～. . . . . . . . . . . . . . . . OA-14

OA-4 Word clouds for the Estate Tax . . . . . . . . . . . . . . . . . OA-16

OA-5 Keywords of Estate Tax by Groups . . . . . . . . . . . . . . . . OA-17

OA-6 Distributional effects of Estate Tax Increase: Who Loses if the Estate Tax were Increased? OA-19

OA-7 Probability of Mentioning Topics . . . . . . . . . . . . . . . . OA-20

OA-8 Topic Distribution by Political Affiliation for the Income Tax . . . . . . . . . . . . . . OA-22

OA-9 Topic Distribution by Income Groups for the Income Tax . . . . . . . . . . . . . . . OA-23

OA-10 Topic Distribution by Age Group for the Income Tax . . . . . . . . . . . . . . OA-24

OA-11 Topic Distribution by Political Affiliation of the Estate Tax . . . . . . . . . . . . OA-25

OA-12 Topic Distribution by Income Groups of the Estate Tax . . . . . . . . . . . . OA-26

OA-13 Topic Distribution by Age Group of the Estate Tax . . . . . . . . . . . . . . . OA-27 


\section{OA-1 Representativeness of the Sample}

For more details on the surveys, sample, data collection, and data analysis, see Stantcheva (2021). The full questionnaire is in Section OA-2 of the Online Appendix of that paper.

\section{Table OA-1: SAmple Characteristics}

\begin{tabular}{|c|c|c|c|}
\hline & US Population & Income Tax Survey & Estate Tax Survey \\
\hline Male & 0.49 & 0.48 & 0.46 \\
\hline 18-29 years old & 0.24 & 0.23 & 0.22 \\
\hline 30-39 years old & 0.20 & 0.20 & 0.20 \\
\hline 40-49 years old & 0.18 & 0.19 & 0.19 \\
\hline 50-59 years old & 0.19 & 0.21 & 0.19 \\
\hline $60-69$ years old & 0.19 & 0.18 & 0.19 \\
\hline$\$ 0-\$ 19,999$ & 0.13 & 0.15 & 0.16 \\
\hline$\$ 20,000-\$ 39,999$ & 0.16 & 0.19 & 0.19 \\
\hline$\$ 40,000-\$ 69,999$ & 0.21 & 0.23 & 0.24 \\
\hline$\$ 70,000-\$ 109,999$ & 0.20 & 0.19 & 0.19 \\
\hline$\$ 110,000+$ & 0.31 & 0.24 & 0.20 \\
\hline Four-year college degree or more & 0.34 & 0.48 & 0.46 \\
\hline High-school graduate or less & 0.38 & 0.19 & 0.19 \\
\hline Employed & 0.70 & 0.63 & 0.62 \\
\hline Unemployed & 0.03 & 0.07 & 0.06 \\
\hline Self-employed & 0.07 & 0.07 & 0.06 \\
\hline Married & 0.53 & 0.55 & 0.53 \\
\hline White & 0.61 & 0.76 & 0.76 \\
\hline Black/African-American & 0.12 & 0.06 & 0.06 \\
\hline Hispanic/Latino & 0.18 & 0.06 & 0.07 \\
\hline Asian/Asian-American & 0.06 & 0.07 & 0.07 \\
\hline Democrat & 0.30 & 0.34 & 0.35 \\
\hline Republican & 0.26 & 0.31 & 0.30 \\
\hline Independent & 0.42 & 0.33 & 0.33 \\
\hline Voted for Clinton in the 2016 Presidential Election & 0.48 & 0.44 & 0.44 \\
\hline Voted for Trump in the 2016 Presidential Election & 0.46 & 0.44 & 0.44 \\
\hline Sample size & & 2784 & 2360 \\
\hline
\end{tabular}

Notes: This table displays statistics for the overall US population (column 1) and compares it to the characteristics of the samples of the income tax and estate tax surveys (columns 2 and 3). National statistics on gender, age, income brackets, race, education, marital status, and employment status are from the IPUMS-CPS-ASEC dataset for March 2019 (Flood et al., 2020). National statistics on party affiliation for March 2019 are from Gallup (2019). Statistics on 2016 Presidential Election Results are from Leip (2019). See Stantcheva (2021) for details on how the summary statistics are constructed. 


\section{OA-2 Open-ended Questions Wording}

This section provides the open-ended questions that were asked to respondents in the surveys. See Stantcheva (2021) for the full questionnaires.

We now want to ask you a few broader questions. Please use the text boxes below and write as much as you feel like. Your opinion and thoughts are important to us! There is no right or wrong answer.

\section{Income Taxation Survey}

1. When you think about federal personal income taxation and whether the U.S. should have higher or lower federal personal income taxes, what are the main considerations that come to your mind?

2. What would be a "good" federal tax system in your view? What would be the goal of a good tax system?

3. What do you think are the issues with or shortcomings of the U.S. federal income tax system?

4. Which important aspects of the U.S. federal income tax system would you say are not discussed enough in the current policy debate?

5. What do you think would be the effects on the U.S. economy if the federal personal income taxes were increased?

6. Which groups of people do you think would gain if federal personal income taxes on high earners were increased?

7. Which groups of people do you think would lose if federal personal income taxes on high earners were increased?

\section{Estate Tax Survey}

1. The federal estate tax is a tax imposed on the transfer of wealth from a deceased person to his or her heirs. When you think about the federal estate tax and whether the U.S. should have a higher or a lower federal estate tax, what are the main considerations that come to your mind?

2. In your view, what would be a "good" federal estate tax that you would be satisfied with? What would be the goal of a good estate tax system?

3. What do you think are the shortcomings of the U.S. federal estate tax?

4. What do you think would be the effects on the U.S. economy if the federal estate tax were increased?

5. Which groups of people do you think would gain if the federal estate tax were increased?

6. Which groups of people do you think would lose if the federal estate tax were increased?

\section{OA-3 Political Affiliation Categories}

This section reports the questions that we used to construct the political categories of Figure 3, the definition of political categories, summary statistics of the political leanings in the sample.

1. Did you vote in the last presidential election?

Yes; No

2. (If "Yes" to 1) In the last presidential election, supported:

Hillary Clinton; Donald Trump; Jill Stein; Gary Johnson; Other

(If "No" to 1) Even if you did NOT vote, please indicate the candidate that you were most likely to have voted for or who represents your views more closely.

Hillary Clinton; Donald Trump; Jill Stein; Gary Johnson; Other 
3. On economic policy matters, where do you see yourself on the liberal/conservative spectrum? Very liberal; Liberal; Moderate; Conservative; Very conservative

\section{Definition of Variables:}

Trump Conservative: respondent supported Donald Trump in the 2016 presidential elections and has "conservative" or "very conservative" views on economic policy matters.

Trump Moderate: respondent supported Donald Trump in the 2016 presidential elections and has "moderate" views on economic policy matters.

Clinton Moderate: respondent supported Hillary Clinton in the 2016 presidential elections and has "moderate" views on economic policy matters.

Clinton Liberal: respondent supported Hillary Clinton in the 2016 presidential elections and has "liberal" or "very liberal" views on economic policy matters.

Table OA-2: Political Affiliation and Views on Economic Policy Matters IN THE INCOME TAX SURVEY

\begin{tabular}{lcccccc} 
& D. Trump & H. Clinton & G. Johnson & J. Stein & Other & \\
\hline Liberal & $7 \%$ & $54 \%$ & $12 \%$ & $53 \%$ & $15 \%$ & $29 \%$ \\
Moderate & $32 \%$ & $38 \%$ & $62 \%$ & $37 \%$ & $57 \%$ & $39 \%$ \\
Conservative & $61 \%$ & $7 \%$ & $26 \%$ & $10 \%$ & $28 \%$ & $32 \%$ \\
\hline Total & $100 \%$ & $100 \%$ & $100 \%$ & $100 \%$ & $100 \%$ & $100 \%$
\end{tabular}

Notes: The table shows the distribution of the respondents' views on economic policy matters by political candidate supported in the 2016 presidential elections in the income tax survey sample.

\section{Table OA-3: Political Affiliation and Views on Economic Policy Matters} In The Estate Tax Survey

\begin{tabular}{lcccccc} 
& D. Trump & H. Clinton & G. Johnson & J. Stein & Other & \\
\hline Liberal & $8 \%$ & $55 \%$ & $16 \%$ & $43 \%$ & $19 \%$ & $30 \%$ \\
Moderate & $31 \%$ & $38 \%$ & $54 \%$ & $45 \%$ & $58 \%$ & $38 \%$ \\
Conservative & $61 \%$ & $7 \%$ & $31 \%$ & $12 \%$ & $23 \%$ & $32 \%$ \\
\hline Total & $100 \%$ & $100 \%$ & $100 \%$ & $100 \%$ & $100 \%$ & $100 \%$
\end{tabular}

Notes: The table shows the distribution of the respondents' views on economic policy matters by political candidate supported in the 2016 presidential elections in the estate tax survey sample. 


\section{OA-4 Preprocessing Steps}

This section summarizes the preprocessing steps performed to carry out the text analysis. The first step, whose goal is to reduce the number of distinct elements, is common to all three methods, whereas the subsequent steps are specific to each of the methods.

Given an answer $d_{i}$ :

1. Parse $d_{i}$ : lower-case every word, remove punctuation, spaces in excess, numbers, misspelled words, very common words that carry no intrinsic meaning ("stopwords") such as "and," "the," "each," "then".

\section{OA-4.1 Word clouds and Keyness Graphs}

2. Lemmatizing remaining words, i.e. grouping together the inflected forms of a word so they can be analysed as a single item.

- Use the English lemmatization list available in the lexicon package.

- e.g., : "policies" becomes policy, "were" becomes "be" $\rightarrow$ reduces number of distinct textual elements

$\rightarrow$ Output: $\left(\hat{d}_{i}\right)$

3. Remove words coming from the question as well as extra words related to the structure of answer.

- e.g., for the question, "what are your main considerations about income tax system?" : remove "main," "considerations," "income," from the answers, as well as "think," "believe," "should," etc.

4. Transform $\hat{d}_{i}$ into numerical vector $c_{i}$ in which each element is a 2-gram, i.e. a 2-component expression of two words which were separated by 0 or 1 word in the original text. Group together 2-grams which correspond to the same inverted two words. Manually remove 2-grams which have no grammatical foundation and duplicated 2-grams (e.g., "tax tax").

- e.g., take $d_{1}=$ "We should tax the wealthy more and tax the poor less." After steps 1-2-3 becomes: $\hat{d}_{i}=$ "tax wealthy more tax poor less". After step 4 becomes: ['tax wealthy' $=1$, 'tax more' $=2$, 'wealthy more' $=0$ (because it is not grammatically coherent), 'tax poor' $=1$, 'poor people' $=0$, ...]

\section{OA-4.2 Topic Analysis}

2. Reduce remaining words to common root (stemming).

- Use Snowball stemming algorithm

- policies and policy become polic $\rightarrow$ reduces number of distinct textual elements.

$\rightarrow$ Output: $\left(\hat{d}_{i}\right)$

3. Transform $\hat{d}_{i}$ into numerical vector $\mathbf{c}_{i}$ in which each element is the count of a distinct word.

- e.g., take $d_{1}=$ "We should tax the wealthy more and the poor less."

* After Steps 1-2 becomes: $\hat{d}_{1}=$ "tax wealthi more poor less"

* After Step 3 becomes: ['tax' $=1$, 'wealthi' $=1$, 'more' $=1$, 'poor' $=1$, 'less' $=1 \ldots$ ]

4. Generate topic dummy variables equal to 1 when an element of $\mathbf{c}_{i}$ matches a custom-made topic dictionary. 


\section{OA-5 Methods}

\section{OA-5.1 Word clouds}

The simplest text analysis consists in plotting "word clouds," which are based on a frequency analysis. The frequency of each identified n-gram is computed and the feature label is plotted proportional to this frequency. The word clouds and keyness figures are based on the package by Benoit et al. (2018). The transparency and font size are proportional to the frequency of each group of words relative to the total.

Pros and Cons. Word clouds are a key tool for visualizing responses to open-ended survey questions. The font size of a word group is displayed proportionally to its frequency, yielding an insightful starting point for the analysis of text (Heimerl et al., 2014).

By clearly presenting which themes seem to be common among people's answers, word clouds can equip researchers with a first intuition for topics that could be fruitful to explore further. This quick assessment of answers is particularly useful when analyzing large text corpora in the age of Big Data, or in our case, a large number of open-ended responses to survey questions.

This approach, however, comes with certain drawbacks. For instance, word clouds do not account for synonyms, i.e., they will fail to link only slightly different words to the same underlying idea. As a result, themes that can be described in various ways will be less prevalent in the word cloud, while the importance of topics that are clearly associated with certain "buzzwords" might be over-represented. Beyond that, word clouds take the individual words out of context, potentially leading to a loss of interpretability or meaning. Overall, word clouds are a useful way to visualize and explore textual data. It would be premature, however, to draw any final conclusions about the importance of topics simply based on the font size of occurring words. Instead, the themes communicated in word clouds should be seen as a first step in text analysis and used as cautiously-interpreted guidance for further analysis.

\section{OA-5.2 Keyness and keyword graphs}

Related Literature. We draw on an in-depth overview by Gabrielatos (2018), which describes the history of keyness analysis and provides a critical review of its applications. In addition, Stubbs (2010) digs into the notion of "keywords," which parallels the idea of keyness.

Among the first to conduct keyness analysis is Leech and Fallon (1992), who study the drivers of differences between cultures by comparing corpora in American and British English. Today, keyness analysis is understood primarily as a comparison of frequencies of words in the so-called study and reference groups. This approach can be used to elicit degrees of similarity or difference between the studied groups (Gentzkow and Shapiro, 2010; Taylor, 2013; Partington, 2014).

The keyness graphs in this paper are based on a relative frequency analysis that compares the use of n-grams identified in the corpus between two groups (a reference and a target group). To establish the keyness score of a given item, we establish its frequency relative to the number of words in the group corpus (i.e., the number of words in all the answers of a given group). Those frequencies are cross-tabulated and a $\chi^{2}$ test is conducted to test the independence between the two groups' distribution.

Consider a given n-gram $i$. Let $j$ be the group index, with $j=0$ for the reference group and $j=1$ for the target group. Let $A_{i, j}$ be the observed number of occurrences of the n-gram $i$ in group $j$ and $A_{-i, j}$ the observed number of occurrences of all other n-grams (except the one we consider) in this group. Let $R_{i}$ be the total number of occurrences of n-gram $i$ in both groups, $C_{j}$ be the number of occurrences of all n-grams in group $j$, and $N$ the overall number of occurrences of n-grams in both groups.

To perform the test, we first establish the theoretical distribution under the independence hypothesis by computing $E_{i, j}$, the expected frequency of a given n-gram $i$ in group $j$ :

$$
E_{i, j}=\frac{R_{i} \times C_{j}}{N}
$$


and the expected frequency of all other n-grams in group $j$ :

$$
E_{-i, j}=\frac{R_{-i} \times C_{j}}{N}
$$

The $\chi^{2}$ test statistic is:

$$
\chi^{2}=(-1)^{\mathbb{1}\left\{E_{-i, 1}>A_{-i, 1}\right\}} \sum_{k \in\{-i, i\}} \sum_{j=0}^{1} \frac{\left(A_{k, j}-E_{k, j}\right)^{2}}{E_{k, j}}
$$

We compare this statistic to the distribution of a $\chi^{2}$ distribution law with one degree of freedom (i.e., number of groups -1). A given n-gram is significant when the independence hypothesis is rejected and the n-gram is considered a "keyword." A negative $\chi^{2}$ indicates that the word is significantly more frequent in the reference group. In absolute value terms, the null hypothesis is rejected at the $10 \%$ level when $\left|\chi^{2}\right|>2.71(*)$, at the $5 \%$ level when $\left|\chi^{2}\right|>3.84\left({ }^{* *}\right)$ and at the $1 \%$ level when $\left|\chi^{2}\right|>6.63(* * *)$.

Pros and Cons. Keyness analysis is particularly useful when the goal is to compare text corpora associated with different groups. It is based on a relative frequency analysis that compares the use of words between two groups, for example, Democrats and Republicans in our study.

This simple method allows us to compute a keyness score that measures how characteristic an n-gram is for a given group. Based on this, keyness analysis can be used to establish differences (similarities) between groups. It also allows the researcher to extract notions and attitudes that are at the heart of a given group's text corpus. Thus, this method can, for instance, help elevate our understanding of what drives polarization within the political spectrum.

One common critique of keyness analysis is that it is based purely on statistical significance and does not take into account the effect size (Gabrielatos and Marchi, 2011; Kilgarriff, 2001). In particular, we do not learn about the size of a frequency difference (Gabrielatos, 2018).

Overall, keyness analysis serves as a valuable tool when the goal is to explore potential heterogeneity, e.g., in attitudes across groups. Yet, results need to be interpreted with caution, given the limitations of the method (Gabrielatos, 2018). Indeed, while statistical significance is a useful metric, its utility is limited to express the accuracy of a given frequency difference. Furthermore, keyness is not an intrinsic attribute of words but depends on several subjective decisions regarding, for instance, the size of the linguistic units that are the focus of the analysis, the target and reference text corpora, and the statistical significance thresholds.

\section{OA-5.3 Topic analysis}

Related Literature. Topic analysis was originally developed as a tool for text mining with the goal to impose structure on the rapidly expanding textual data on the internet (Baeza-Yates et al. (1999)). Salton and McGill (1983) introduced a now widely-applied method that compares a normalized word frequency count, within one document, to an inverse document frequency count within a text corpus containing all considered documents. To reduce the dimensionality of vast text corpora, Deerwester et al. (1990) introduced latent semantic indexing (LSI), a method later advanced by Hofmann (1999) into the probabilistic LSI (pLSI). Another approach to topic modeling is the latent Dirichlet allocation (LDA), developed by Blei et al. (2003). Further developments include dynamic topic models (Blei and Lafferty (2006)) and supervised topic models (Blei and Jon (2007)). A more recent advancement was driven by Roberts et al. (2013) and Roberts et al. (2014), who introduce structural topic models and apply the method to open-ended survey responses.

Topic analysis is a versatile tool that can be applied to a wide range of bodies of text. Like keyness analysis, it allows to study heterogeneity in topics use across groups, but its advantage is that we can also flag topics for which the frequency of use is similar across the different groups.(Roberts et al. (2014)). For more comprehensive reviews of the limitations of topic analysis and potential solutions, see Tang et al. (2014) and Agrawal et al. (2018).

Semi-supervised approaches to topic modeling allow the researcher to suggest a set of words around which the algorithm attempts to build topics. Including additional information, e.g., from external data sources, 
in the topic modeling process can significantly improve classification results. Banerjee et al. (2007) and Schönhofen (2009) draw on the titles and categories of Wikipedia articles, as an external data source, to improve the clustering accuracy of their documents.

To improve the interpretability of topics, Lu et al. (2011) propose an algorithm that is closely related to Latent Dirichlet Allocation (LDA). Another approach, referred to as "Newsmap" and based on naive Bayes classifiers, was introduced by Watanabe (2018b) and implemented in Watanabe (2018a). Both the seededLDA and the Newsmap models were employed in Watanabe and Zhou (2020). Finally, Gallagher et al. (2017) develops a novel approach that does not require assumptions about the underlying data generation process: the "Correlation Explanation" (CorEx) Topic Model.

Semi-supervised algorithms reduces the amount of hand-coding necessary by the researcher and are by nature, data driven. Nevertheless, there are always decisions to be made. For instance, one needs to chose how fine-grained or coarse to make the topics, whether to use the same keywords across time (e.g., newspaper articles across decades) and across people (e.g., groups that may use different language), or rather adapt them.

For open-ended survey questions, it can make sense to pick topics manually, because the answers are shorter than most of the texts that topic analysis has been used for. It is of course then possible to cross-validate the results using less supervised methods. When topics are chosen with a more hands-on approach, multiple hypothesis testing may become a concern Roberts et al. (2014), but could possibly be alleviated thanks to a pre-analysis plan. In practice, we use a manual approach.

Our approach. As a first preliminary step, we extract the document-term matrix (DTM). The DTM is a mathematical matrix that describes the frequency of terms that occur in a given set of documents (in our case, a document coincides with the answer of a given respondent to a given question). The rows and columns correspond to documents and terms, respectively. Hence, the element $(x, y)$ in the DTM corresponds to the frequency of the term $y$ in question answer $x$.

Topics are then defined by sets of keywords that aim to capture the particular aspects of the policy with which the respondent is concerned when answering to the question. We fix these topics based on the distribution of words that we see in the answers (i.e., in the DTM) and on our understanding of the issues studied. It is critically important to read many sample answers in order to better understand how respondents are interpreting the question and how they are using specific terms. The topic indicator variable is equal to one if the document contains at least one of the keywords that define the topic. Documents can thus contain more than one topic if the respondent used keywords belonging to different topics.

\section{OA-6 Topic Keywords}

In this section, we provide the full list of keywords used to define the topics presented in Figure 2 and in Figures OA-8 to OA-13 of this Online Appendix. 


\section{Table OA-4: Keywords Defining the Income Tax Topics}

Distribution:

Fairness:

Government spending:

Social insurance:

Efficiency:

Flat tax:

Loopholes:

Public goods:

Don't know:
Middle class; working class; low income; wealthy; millionaire; rich; billionaire; corporations $\& 5$ pay/tax

Fair; unfair

Government spending 83 high; government spending $\&$ cut; deficit; debt; government $\mathcal{E}$ waste; balance $\mathcal{E}$ budget; government $\mathcal{E}$ budget; government 83 control $\&$ spend

Social services; governmental services; governmental program $\&$ fund; governmental program $\& 3$ cover; help $\mathscr{E}$ poor; pay $\& 3$ poor; social program; poor work; live $\mathcal{B} 3$ paycheck; provide $\mathcal{G}$ family

Hurt $\&$ economy; work hard; work less; work more; create $\mathcal{E}$ job; depress; trickle down; negative/detrimental/destroy/damage \& economy; competition; innovation; create $\mathcal{E}$ business; boost $\mathcal{E}$ economy; discourage; spend less

Flat tax

Loopholes; lawyer; account; tax evasion; evade; avoid taxes

Infrastucture; education; healthcare

Not know; knowledgeable enough; idk; not sure; know enough; unsure

\section{Table OA-5: Keywords Defining the Estate Tax Topics}

Distribution:

Fairness:

Government spending:

Efficiency:

Loopholes:

Double tax:

Grieve:

Public goods:

Don't know:
Middle class; working class; low income; wealthy; millionaire; rich; billionaire; corporations 83 pay/tax; poor; inequality

Fair; unfair

Government spending $\&$ high; government spending $\&$ cut; deficit; debt; government $\mathcal{E}$ waste; balance $\mathcal{E}$ budget; government $\mathcal{E}$ budget; government Es control 85 spend

Hurt economy; work hard; flat

Loopholes; lawyer; account; tax evasion; evade; avoid taxes

Already taxed/paid; twice $\&$ tax/pay

Grieve; bury; funeral

Infrastructure; education; health care

not know; knowledgeable enough; idk; not sure; know enough; unsure

\section{OA-7 Sample of Answers to the Open-ended Question "What are your Main Considerations about the Policy?"}

\section{OA-7.1 Income Taxation}

Distribution: "That the rich and wealthy do not pay their fair share of taxes."

"Everyone, including the rich and corporations should pay their fair share."

"I would want working class and middle class people to get tax cuts and I'd be willing to pay more in taxes for that to happen."

Fairness: "I have trouble with the concept of tax brackets that punish an individual for being successful." "I believe Everyone should be taxed fairly and the most wealthy should not escape carrying their weight." 
Government Spending: "Current tax rates being raised are a result of government mismanagement of funds and over spending without appropriate oversight. Taxes really can't effectively be lowered until government spending is properly controlled."

"I am okay with raising personal income tax to reduce deficit but not for entitlement programs."

Social safety net: "What are the taxes going towards? I strongly believe in funding going towards education and infrastructure."

"Cut government spending on social welfare programs for lower taxes and privatize most government services for lower taxes e.g., mail, law enforcement, parks, schools..."

Effiency: "I am concerned about the push to raise taxes on persons with higher incomes. I do believe in trickle down economics and that government should pretty much keep their hands off."

"I want the U.S. to be competitive for businesses, but also know there needs to be an appropriate amount of money to fund the government necessities."

Flat Tax: "We need a flat tax. Tax forms are complex."

"I think tax Rates are not fairly representative for most taxpayers. I support a flat tax rate for all except the totally disabled and indigent."

Loopholes: "I think the more you make, the more you should pay. We need to close the loopholes that are there to make sure that those who make more actually pay more."

"The wealthy oligarchs who own this country will never allow their taxes to be raised, or will hire tax lawyers to get out of paying them, so any raise in federal personal income taxes will fall on the middle class."

Don't know: "I don't know much about this topic."

\section{OA-7.2 Estate Tax}

Distribution: "It can help keep the ultra wealthy accountable for their wealth."

"Passing wealth from one generation to the next contributes to wealth inequality. Federal estate tax should be much higher."

Fairness: "I don't think there should be a federal estate tax because it's kind of unfair to have to pay taxes on money that already belongs to your family and has most likely had taxes paid on it already."

Government spending: "I believe in smaller government, so all taxes should be lower. I actually think we should have a flat tax for income - period. Then estate taxes wouldn't even be an issue."

Public goods: "I would like higher taxes to pay for more domestic spending such as education, healthcare, etc."

Efficiency: "Lower taxes mean I have more disposable income to spend therefore more products can be mad and more jobs created. I feel it is wrong to penalize people for increased wealth."

Loopholes: "The wealthy don't ususally pay these taxes, they find a loophole. Why should my children have to pay taxes on things I've already paid taxes on during my lifetime?"

Double taxation: "I think it is ridiculous, you pay taxes twice."

Grief: "I don't think we should have one at all. You're taxing a family member for the death of their loved one? That's messed up." 


\section{OA-8 Additional Figures}

Figure OA-1: Word Clouds for the Income Tax

(a) What are your Main Considerations ABOUT THE INCOME TAX?

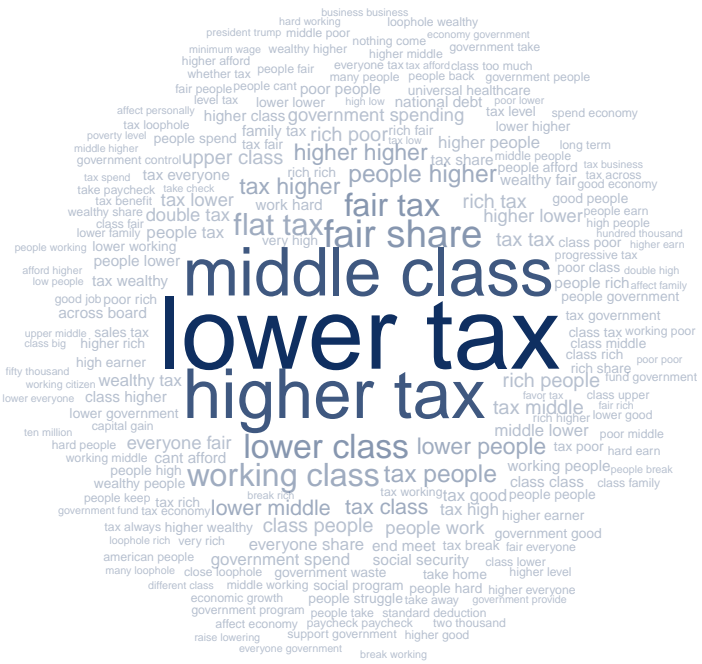

(B) What would Be the Goal of a Good InCOME TAX System?

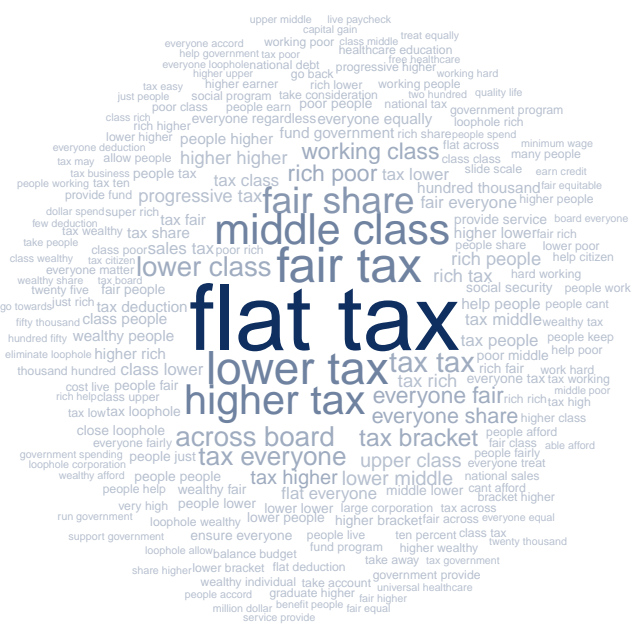

(c) What are the Shortcomings of the Income Tax System?

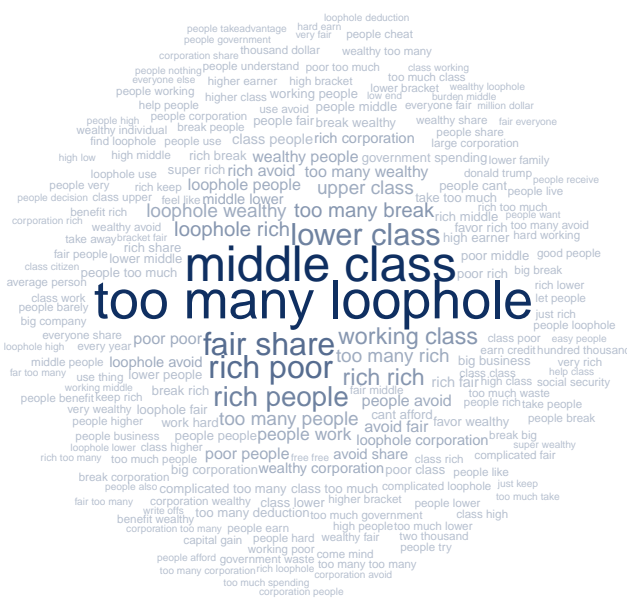


(D) WHich IMPORTANT ASPECTS OF THE U.S. FEDERAL INCOME TAX SYSTEM WOULD YOU SAY ARE NOT DISCUSSED ENOUGH IN THE CURRENT POLICY DEBATE?
(E) What Do You THINK WOULD BE THE EFFECTS ON THE U.S. ECONOMY IF THE FEDERAL PERSONAL INCOME TAXES WERE INCREASED?
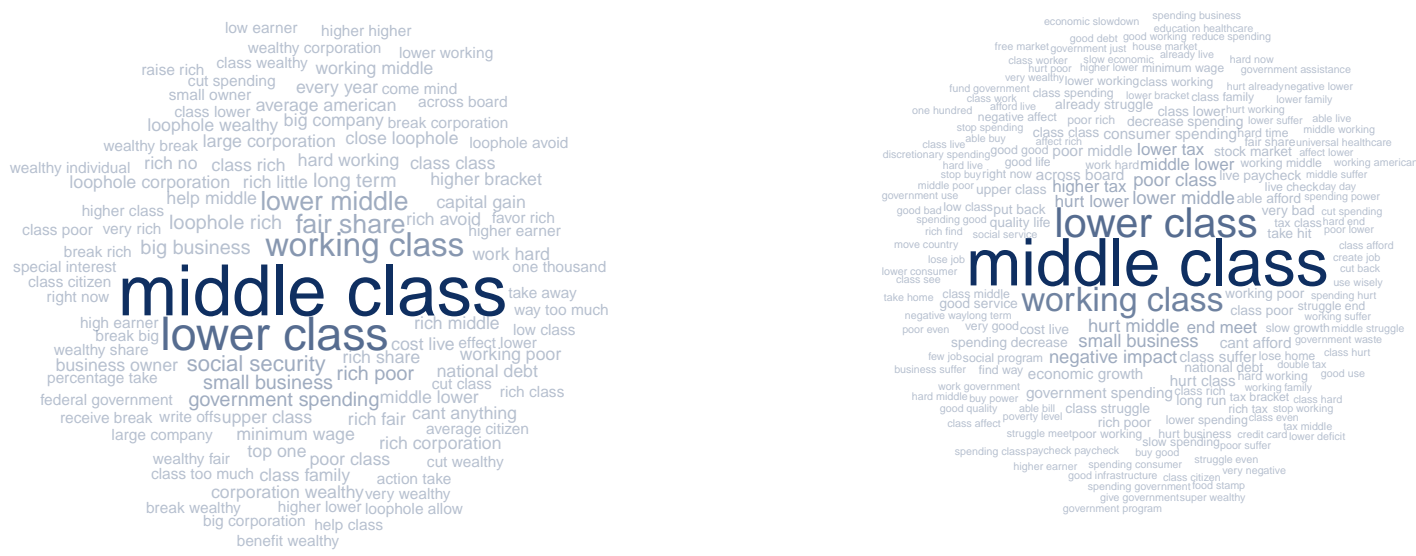

Notes: Word clouds based answers to open-ended questions stated in the caption. See Section OA-5.1. 
Figure OA-2: Distributional effects of Income Tax Increase: Who Gains if TAXes on High EARners Were to Be InCREASED?

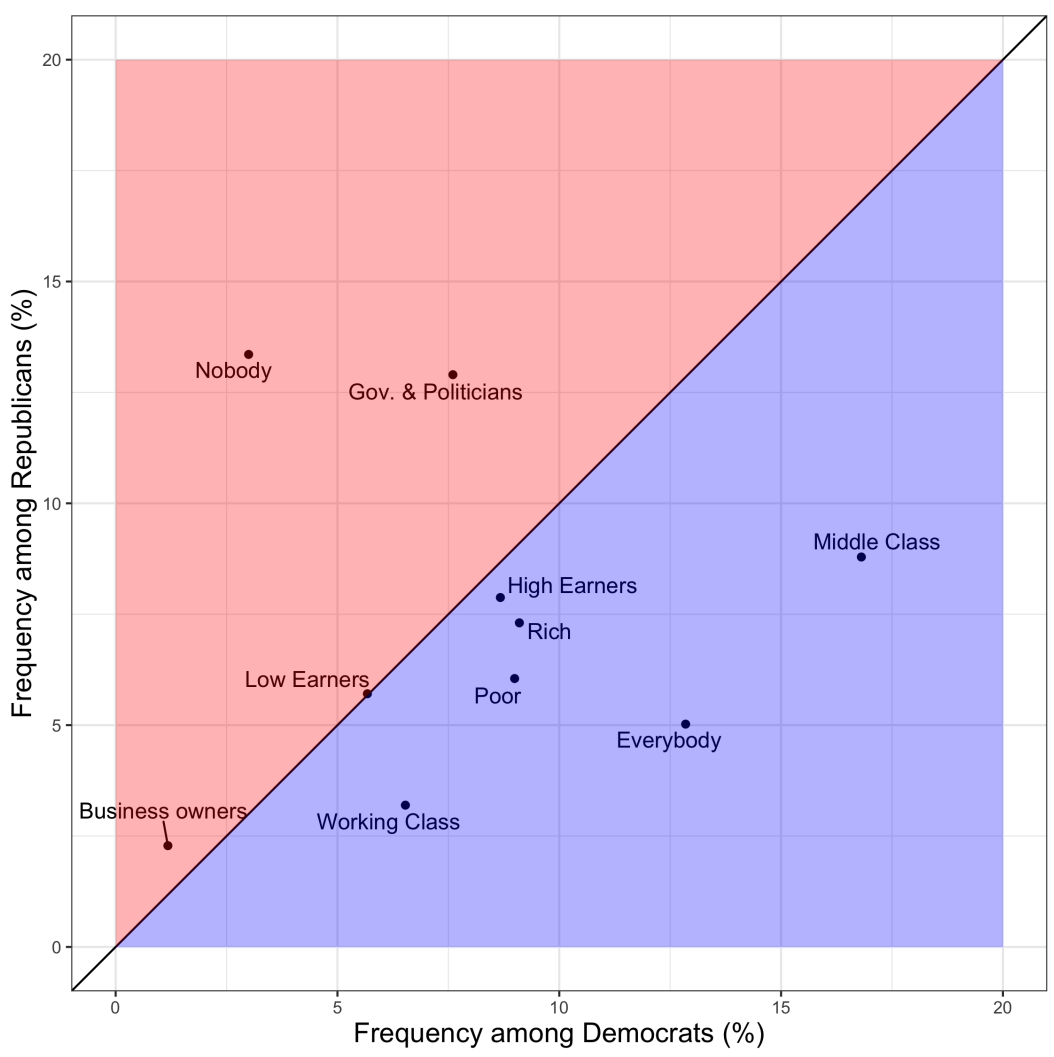

Notes: The figure reports raw frequencies among Democrat and Republican respondents of the groups mentioned when answering to the question "Which groups of people do you think would gain if federal personal income taxes on high earners were increased?" 
Figure OA-3: Keywords of Income Taxation by Groups

(A) By Political Affiliation

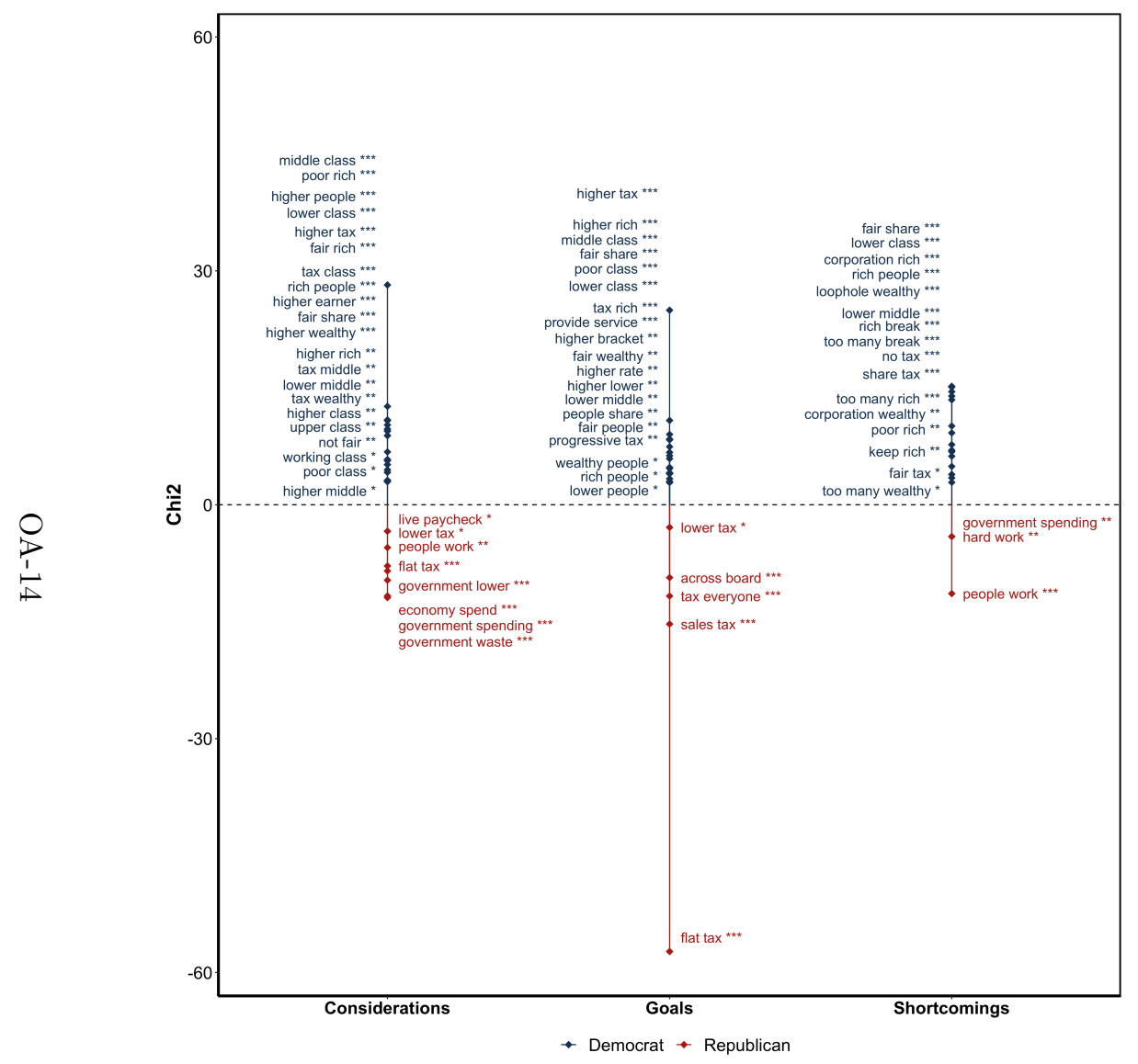

(B) By Age Group

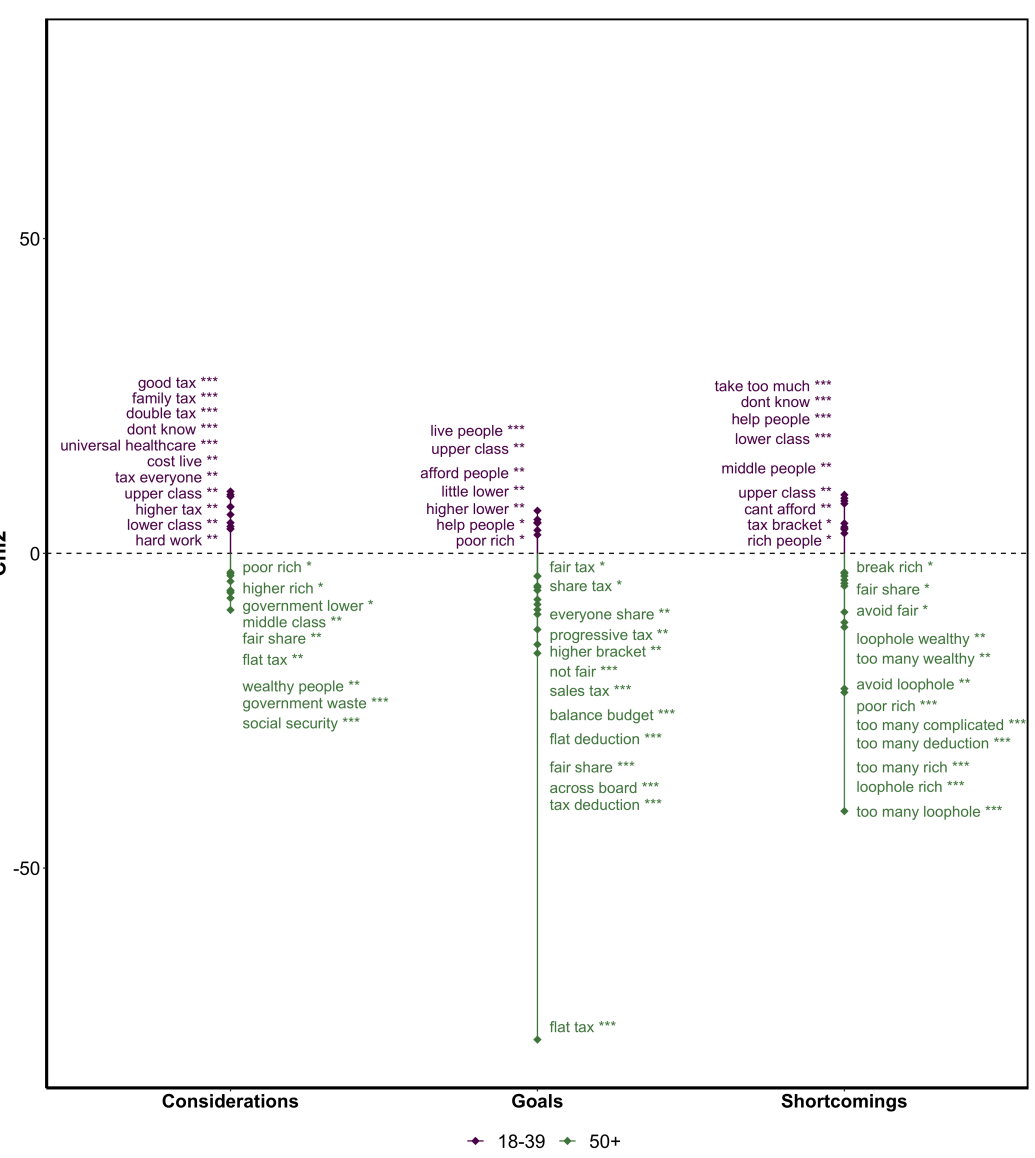


(c) By Perceived Social Class

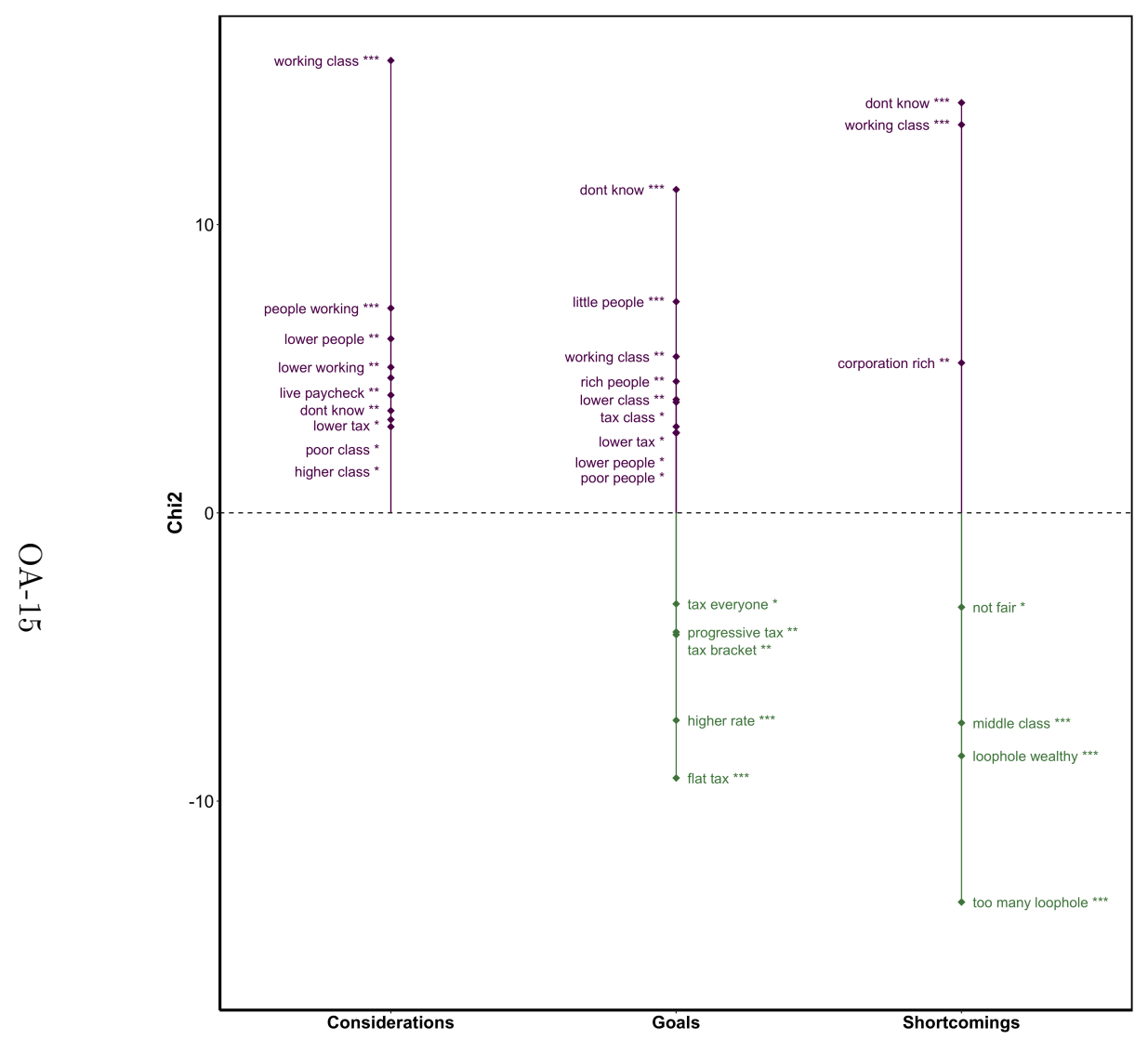

$\rightarrow$ Lower or Working Class $\rightarrow$ Upper-middle or Upper class
(D) By Education Level

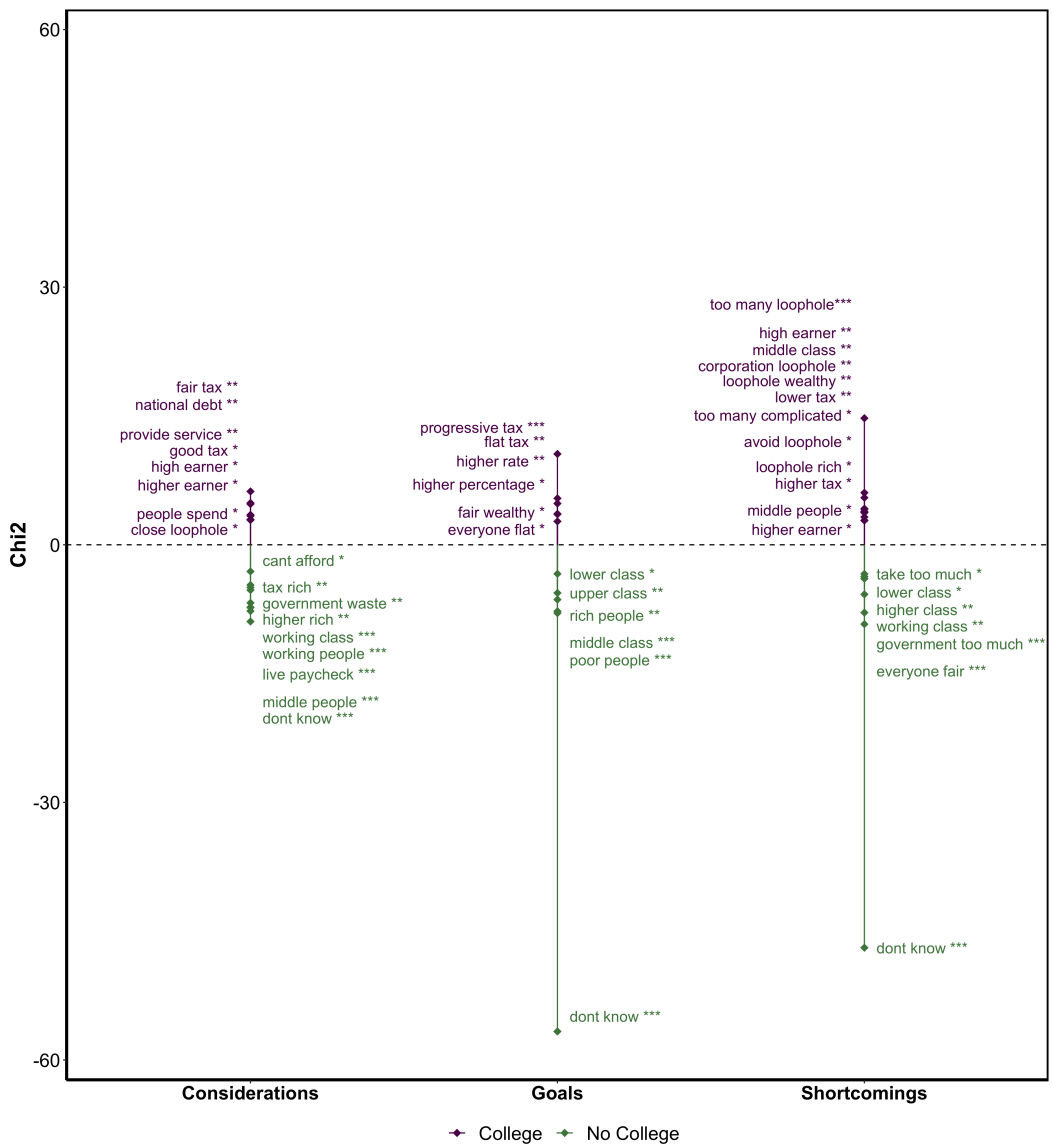

Notes: The figure shows keywords among different groups of respondents in answers to the questions about respondents' main considerations, desired goals, and shortcomings of the income tax. See Section OA-2 for the full text of the questions. The groups are defined by political affiliation, age, perceived social class, and education level, respectively. The score reported for a set of two words is the $\chi^{2}$ - test statistic, testing the null hypothesis that the occurrence of the given keywords is the same among the two groups. * $p<0.1,{ }^{* *} p<0.05,{ }^{* * *} p<0.01$. See Section OA-5.2. 


\section{Figure OA-4: Word Clouds for the Estate Tax}

(a) What are your Main Considerations about the Estate TAX?

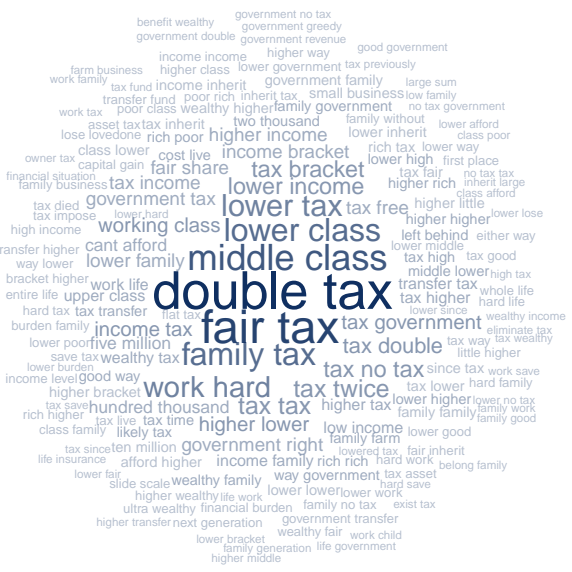

(c) What are the Shortcomings of the Estate Tax System?
(B) What Would Be the Goal of a Good Estate Tax System?

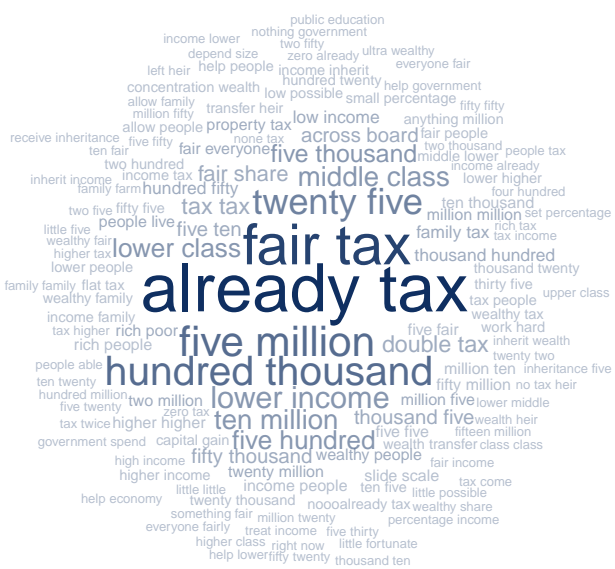

(D) What Do You Think WOUld BE The EFFECTS ON THE U.S. ECONOMY IF THE FEDERAL ESTATE TAX WERE INCREASED?
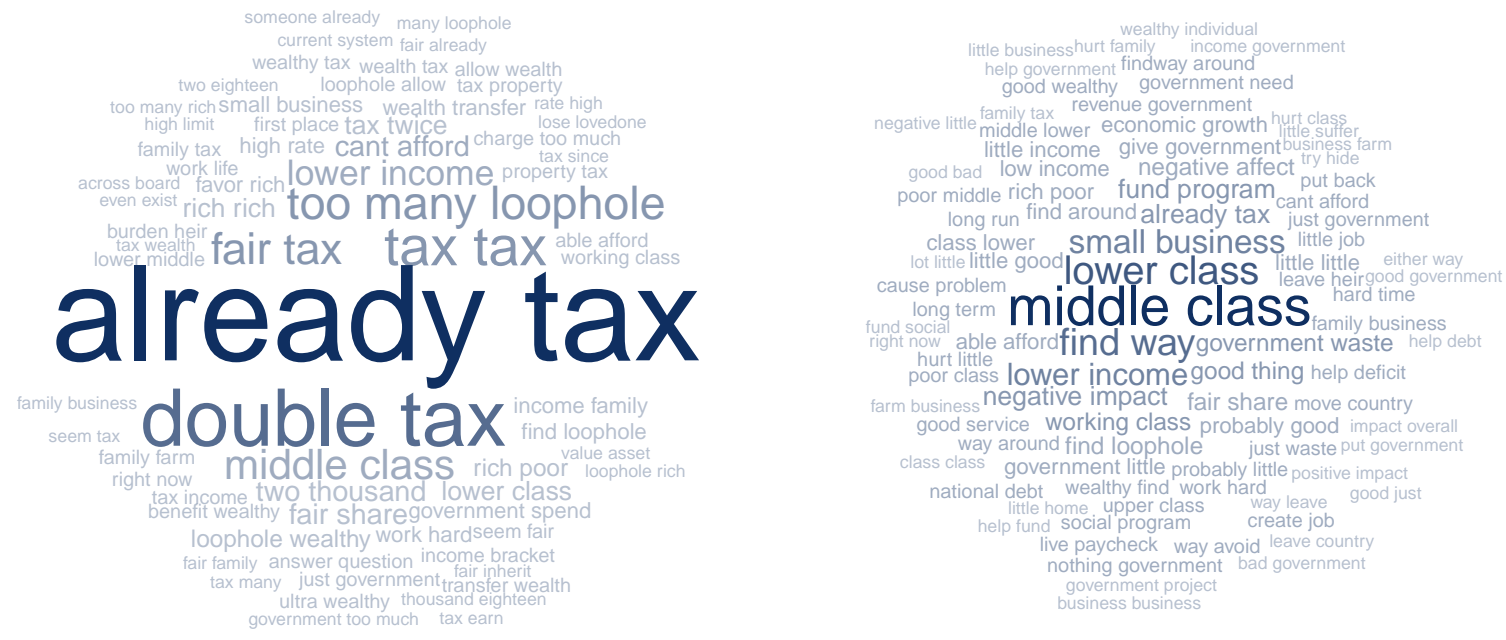

Notes: Word clouds based answers to open-ended questions stated in the caption. See Section OA-5.1. 


\section{Figure OA-5: Keywords of Estate TaX By Groups}

(A) By Political Affiliation

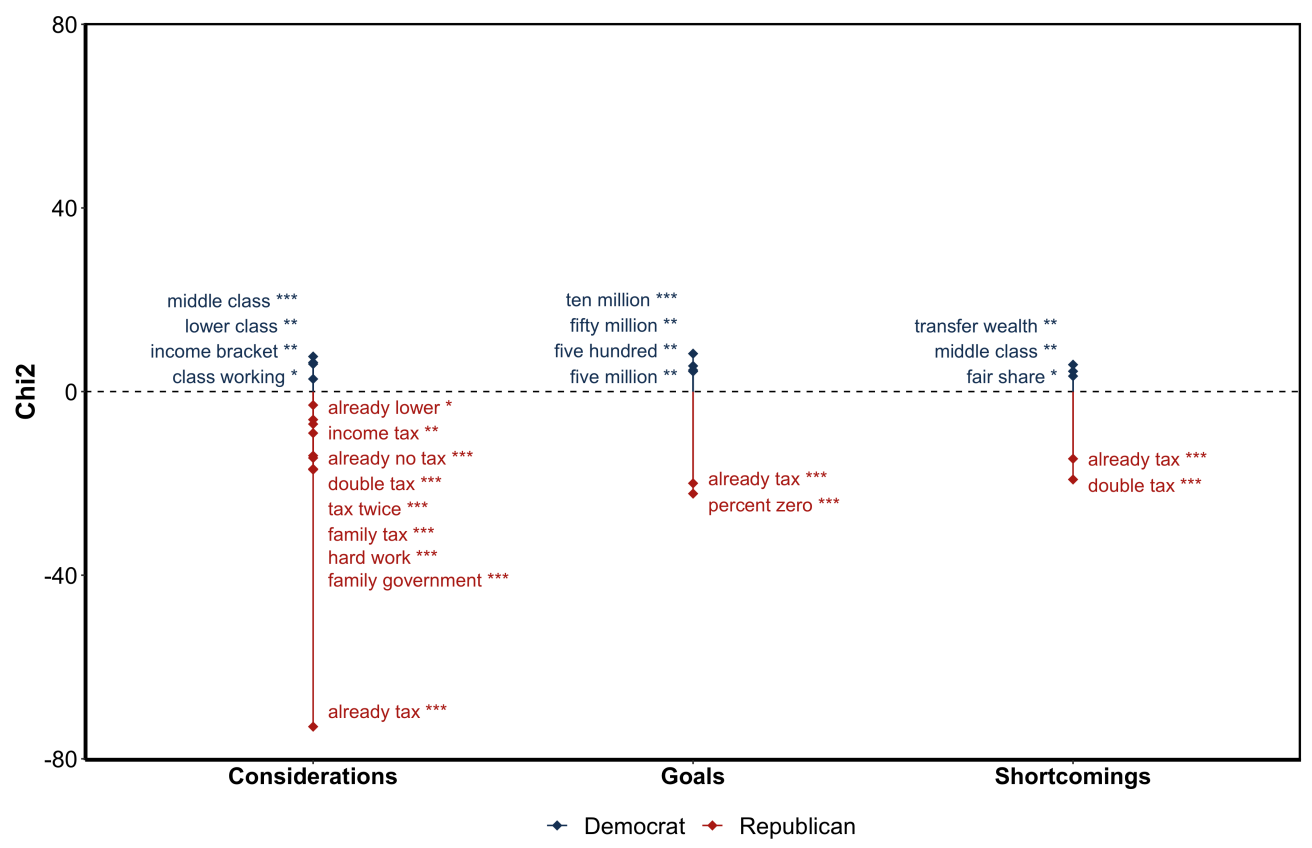

(B) By Age Group

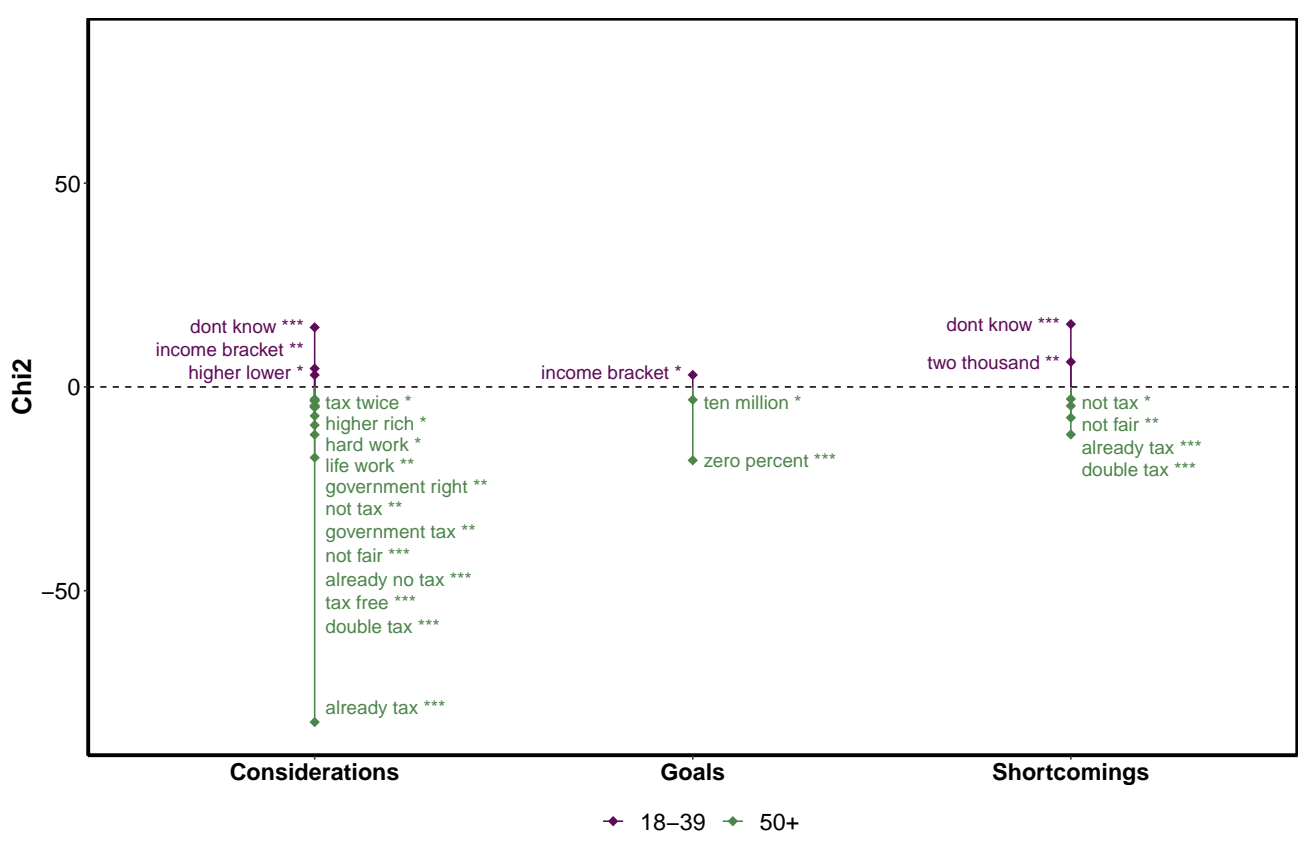


(c) By Perceived Social Class

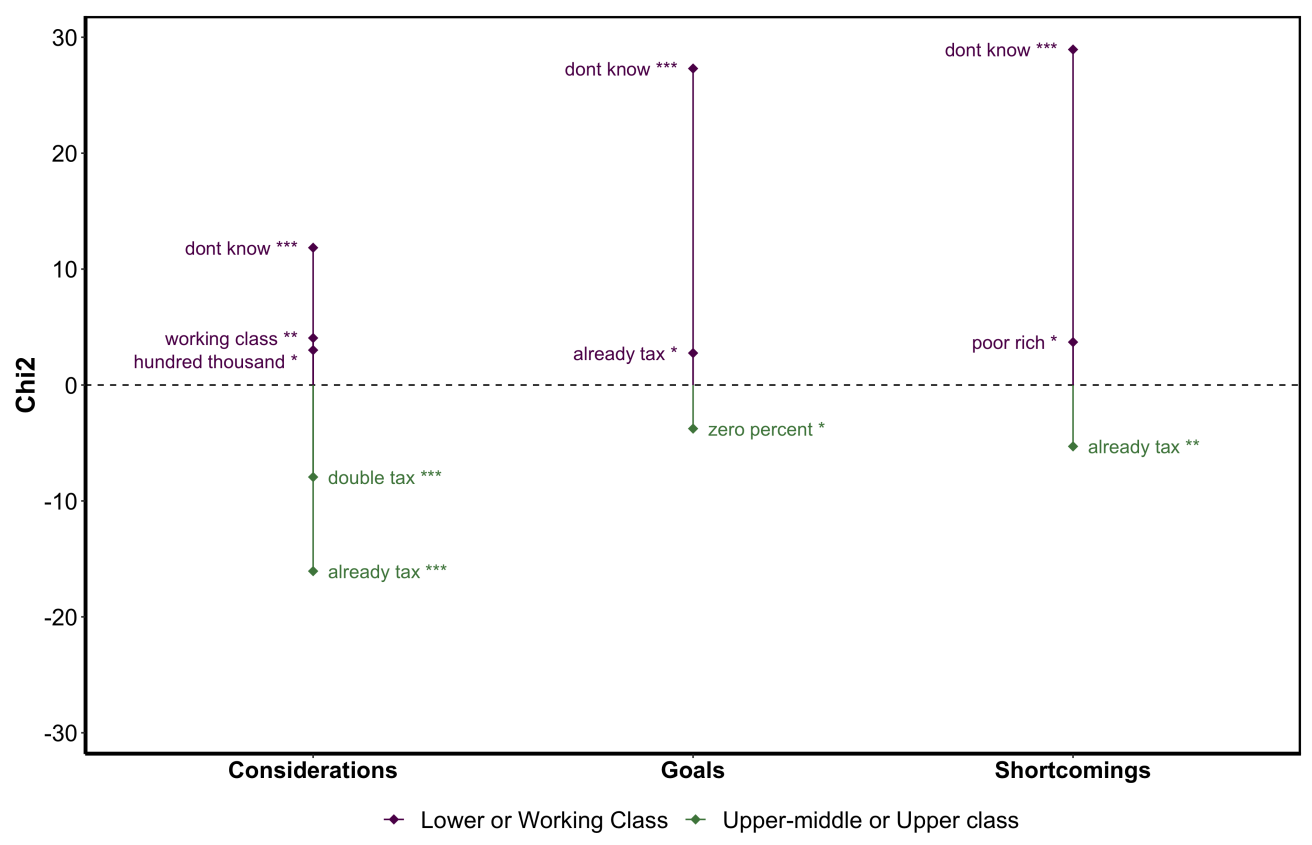

(D) By Education Level

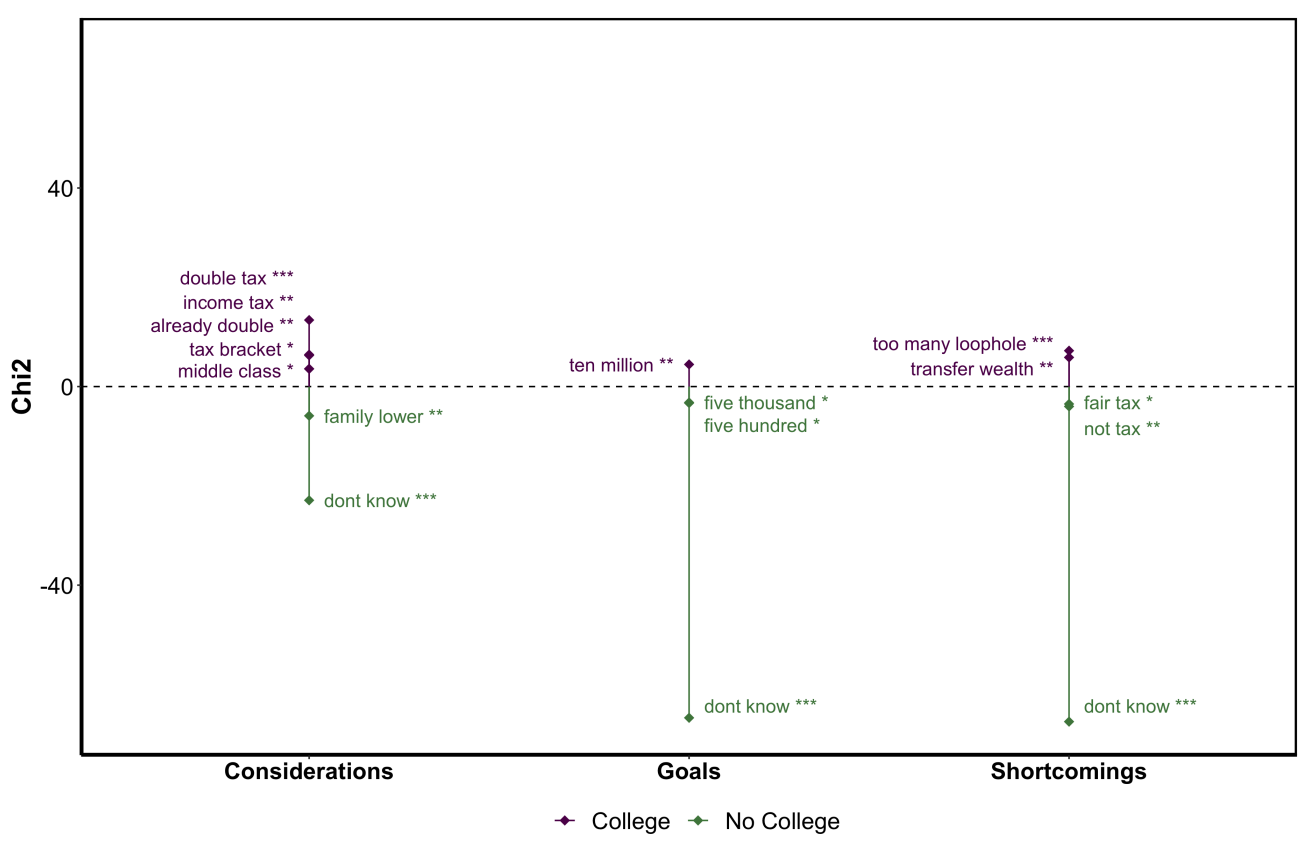

Notes: The figure shows keywords among different groups of respondents in answers to the questions about respondents' main considerations, desired goals, and shortcomings of the estate tax. See Section OA-2 for the full text of the questions. The groups are defined by political affiliation, age, perceived social class, and education level, respectively. The score reported for a set of two words is the $\chi^{2}$ - test statistic, testing the null hypothesis that the occurrence of the given keywords is the same among the two groups. ${ }^{*} p<0.1,{ }^{* *} p<0.05,{ }^{* * *} p<0.01$. See Section OA-5.2. 
Figure OA-6: Distributional effects of Estate Tax Increase: Who Loses if The Estate TaX Were InCREased?

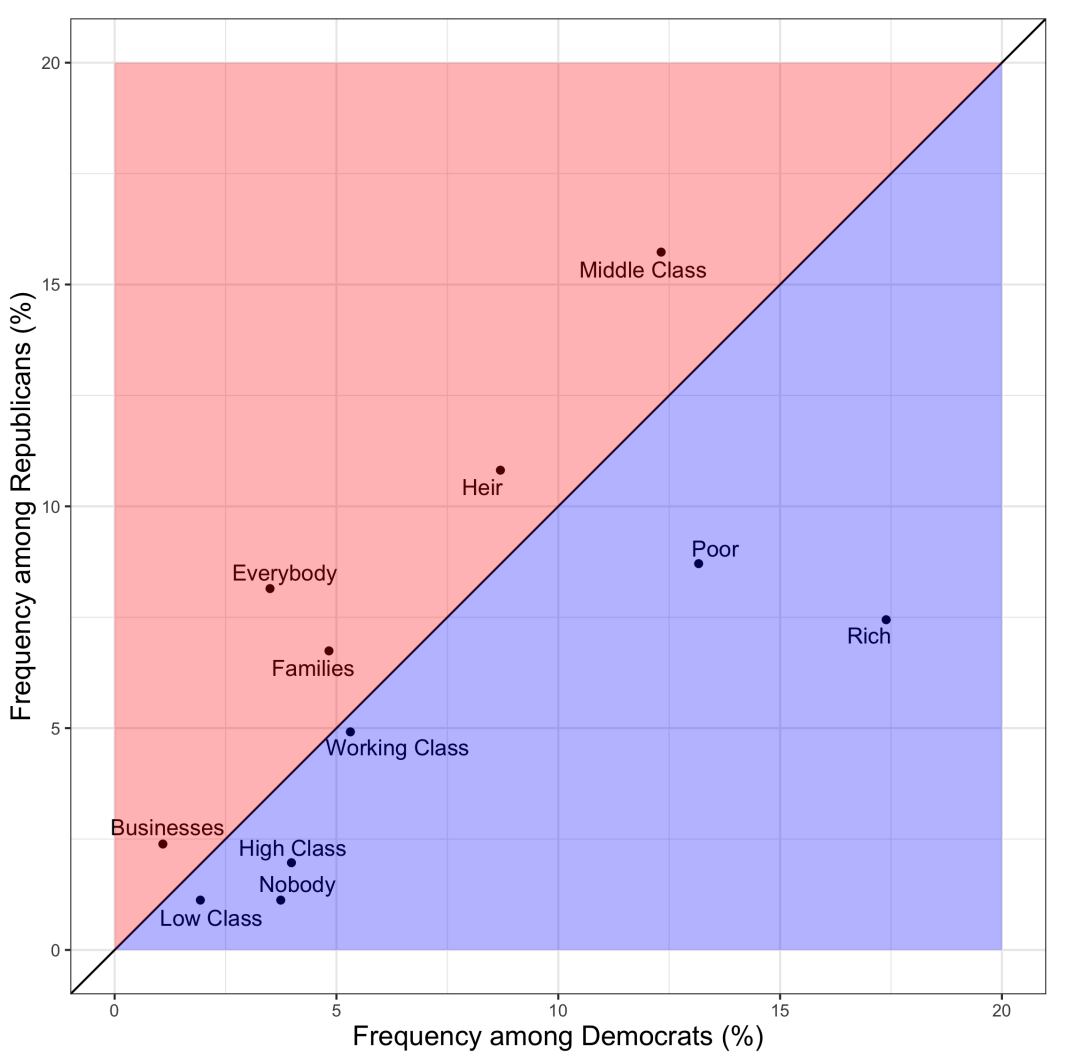

Notes: The figure reports raw frequencies among Democrat and Republican respondents of the groups mentioned when answering to the question "Which groups of people do you think would lose if the federal estate tax were increased?" 
Figure OA-7: Probability of Mentioning Topics

(A) Income TAX

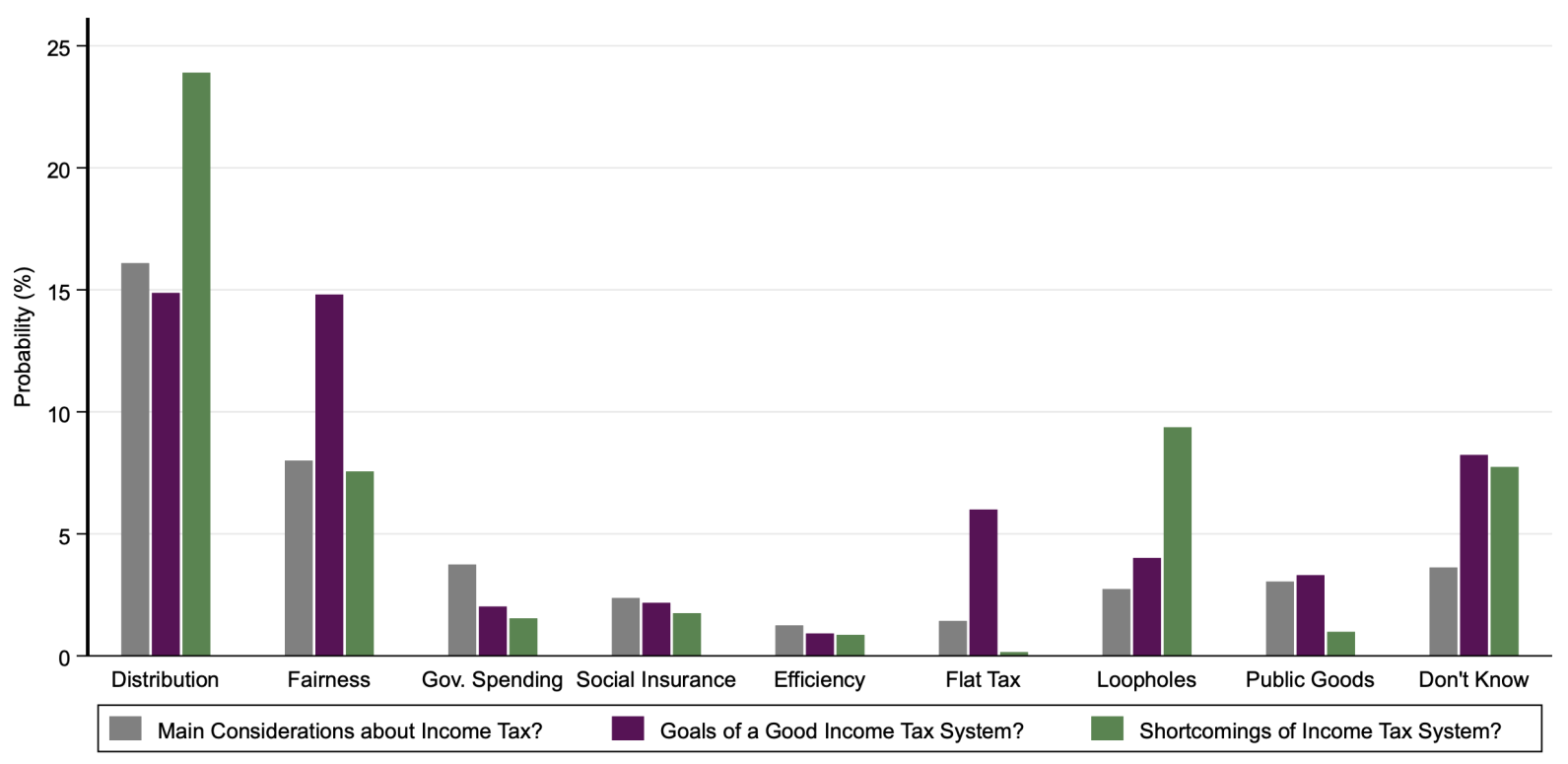


(B) Estate Tax

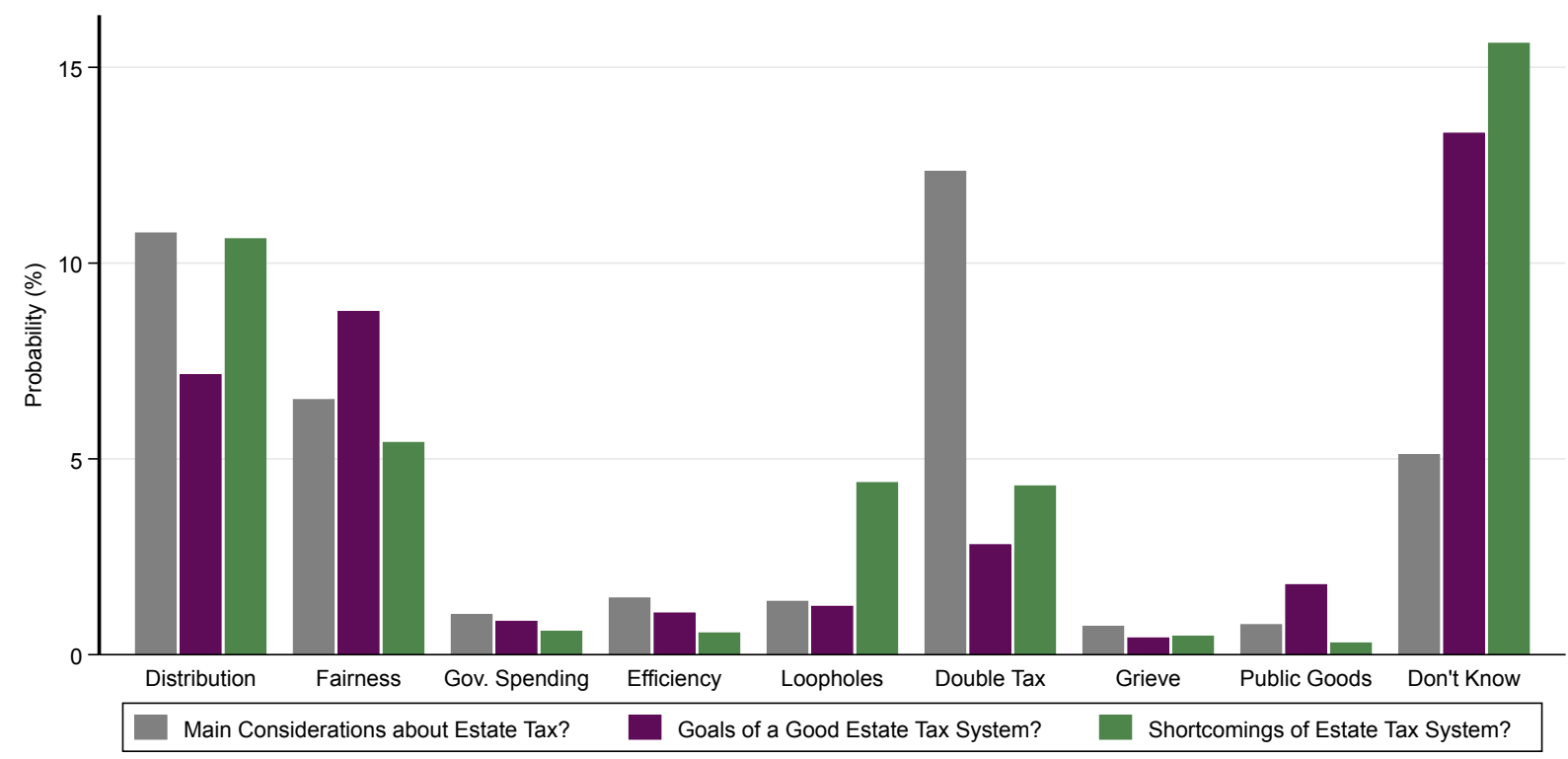

Notes: The figure presents, based on the keyword-based topic analysis, the probability of mentioning topics for three open-ended income and estate tax questions. Each reported topic corresponds to an indicator variable in the keyword-count model, which equals 1 if the respondent mentions in their response at least one of the topic-defining keywords. For the list of keywords and details on the text analysis methodology, see Section OA-6 and see Section OA-5.3. Panel A: Considerations: When you think about federal personal income taxation and whether the U.S. should have higher or lower federal personal income taxes, what are the main considerations that come to your mind?; Goals: What would be the goal of a good tax system?; Shortcomings: What do you think are the issues with or shortcomings of the U.S. federal income tax system? Panel B: Considerations: When you think about the federal estate tax and whether the U.S. should have a higher or a lower federal estate tax, what are the main considerations that come to your mind?; Goals: What would be the goal of a good estate tax system?; Shortcomings: What do you think are the shortcomings of the U.S. federal estate tax? For details on the text analysis methodology, see Section OA-5.3. 
Figure OA-8: Topic Distribution by Political Affiliation for the Income TAX

(a) What are your Main Considerations about the U.S. federal income tax system?

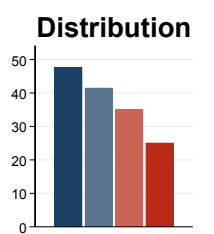

Flat Tax

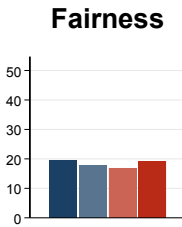

Loopholes

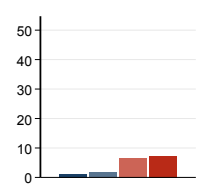

Clinton Libera
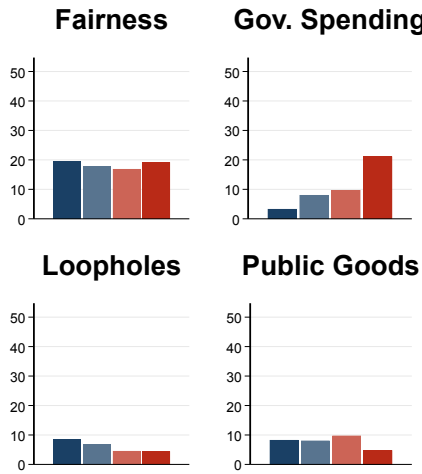

Public Goods

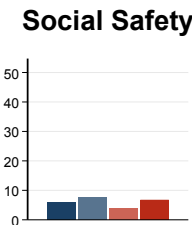

\section{Efficiency}

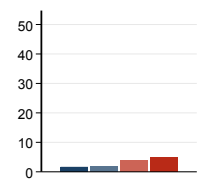

\section{Don't Know}
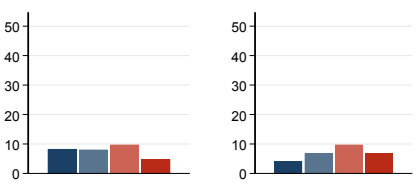

Clinton Moderate

Trump Moderate

Trump Conservative

(B) What WOUld BE THE GOAL OF A GOOD INCOME TAX SYSTEM?

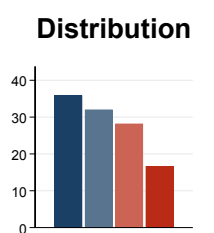

Flat Tax

\section{Fairness}

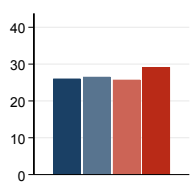

Loopholes

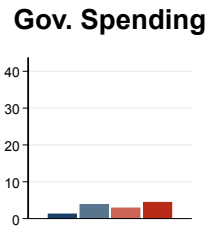

Social Safety

Efficiency
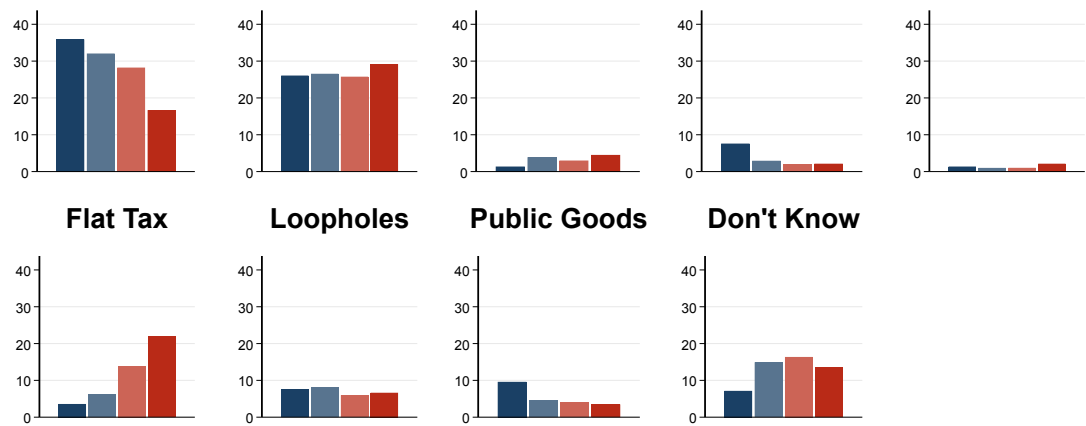

Public Goods

Don't Know
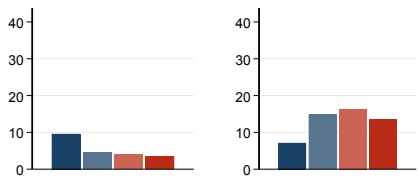

Clinton Liberal Clinton Moderate Trump Moderate

Trump Conservative

(c) What do you think are the shortcomings of the U.S. Federal income tax system?

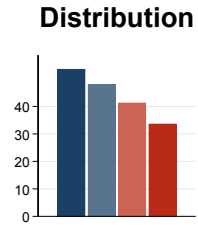

Flat Tax
Fairness

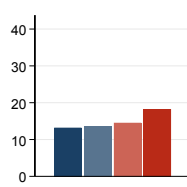

Loopholes

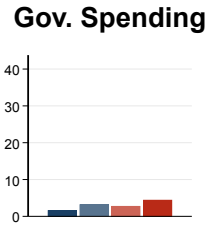

Public Goods
Social Safety

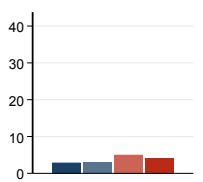

Don't Know

\section{Efficiency}
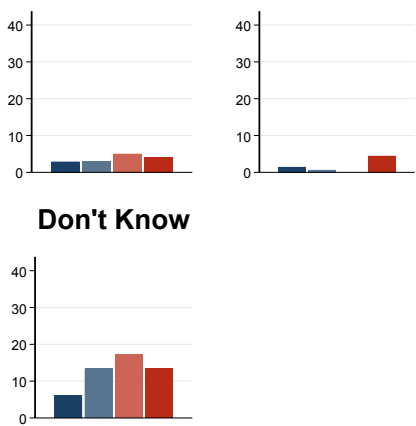

Clinton Liberal Clinton Moderate Trump Moderate

Trump Conservative

Notes: The figure shows distribution of topics mentioned in the answers to the open-ended questions about the income tax by political affiliation. See Section OA-2 for the full text of the questions. The bars represent the number of times a topic was mentioned out of the total mentions of any topic by political group. For the list of keywords and details on the methodology, see Section OA-6 and see Section OA-5.3. 
Figure OA-9: Topic Distribution by Income Groups for the Income Tax (a) What are your Main Considerations about the U.S. federal income tax system?
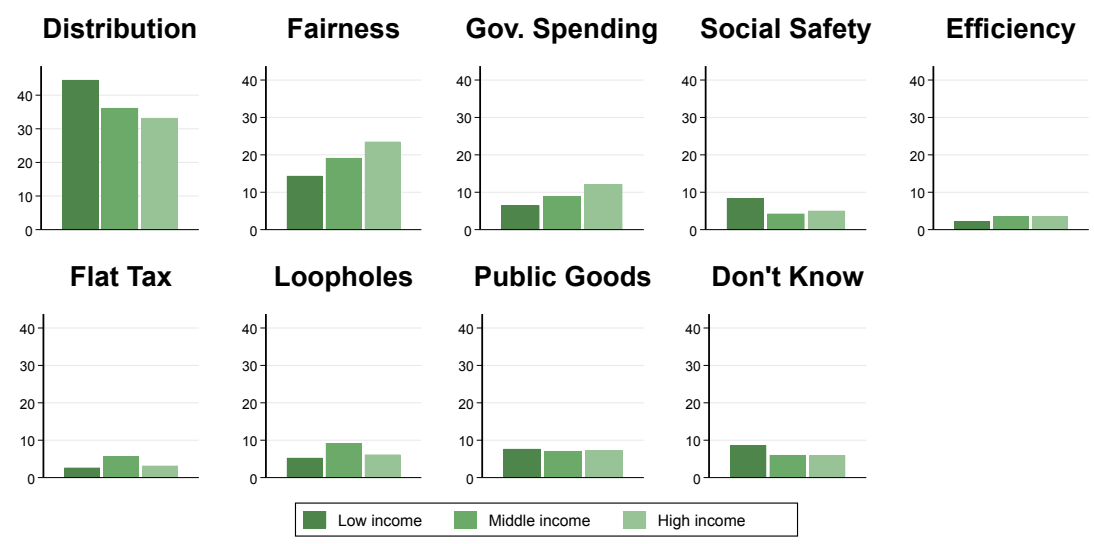

(B) What Would be the GOAl of a GOOD income tax System?
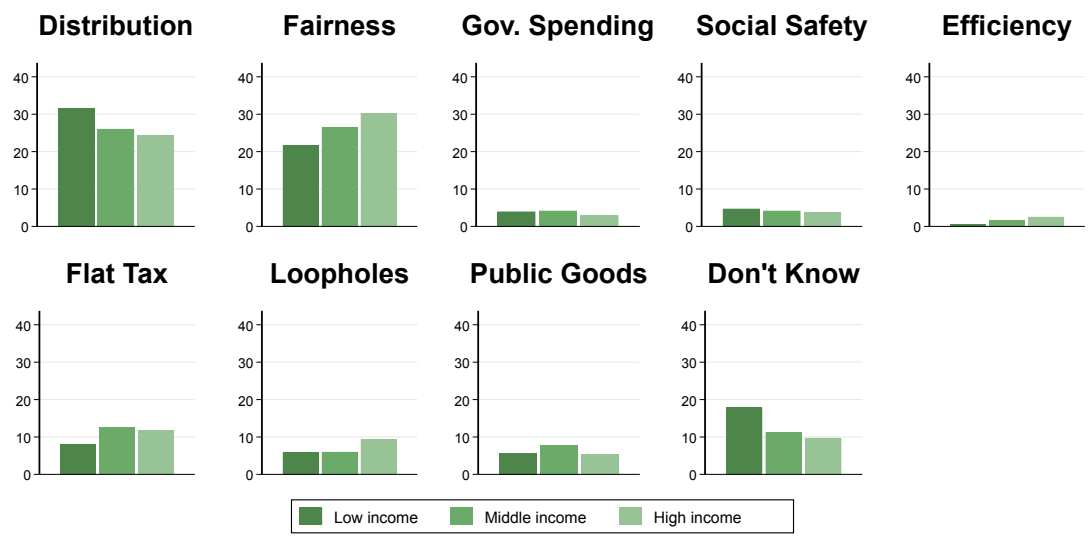

(c) What do you think are the Shortcomings of the U.S. Federal income tax System?
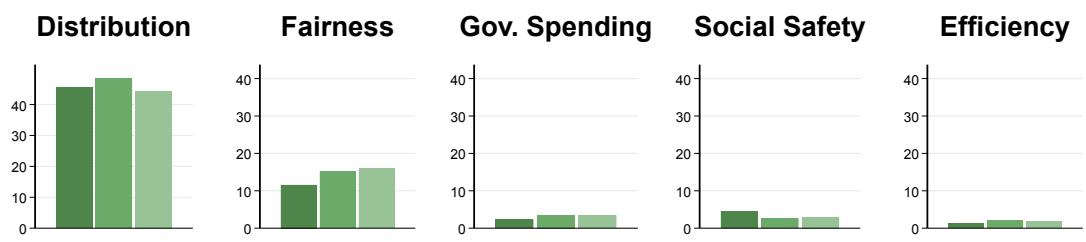

Flat Tax

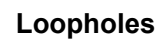

Public Goods
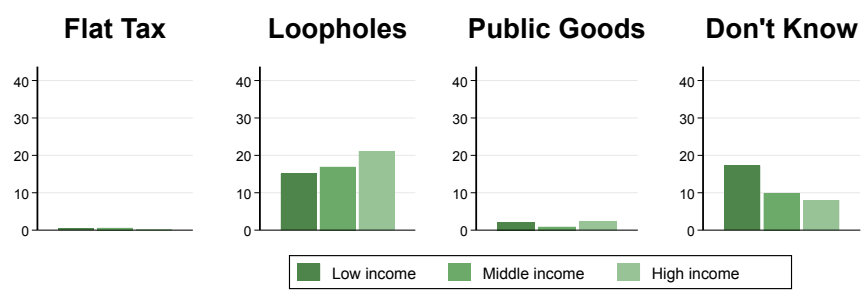

Notes: See the notes to Figure OA-8. Low income (High income) corresponds to respondents who report a pre-tax household income below (above) 39,000 (70,000) U.S. dollars; Medium income corresponds to respondents who report a pre-tax household income between 40,000 and 69,000 U.S. dollars. 
Figure OA-10: Topic Distribution by Age Group for the Income Tax (a) What are your Main Considerations about the U.S. federal income tax system?
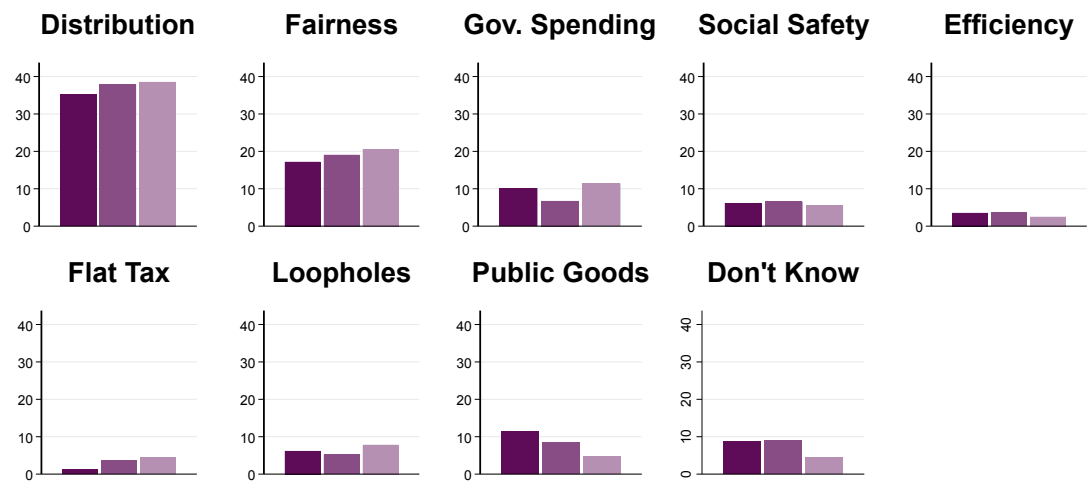

Public Goods
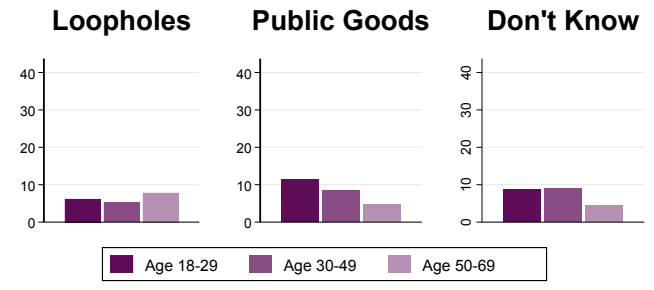

(B) What would be the goal of a good income tax System?
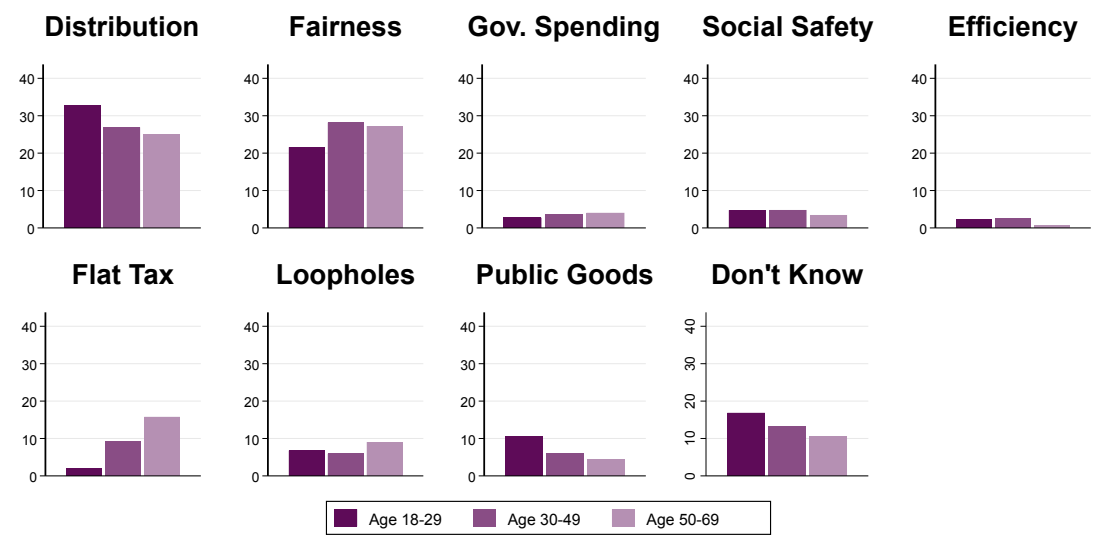

(c) What do you think are the Shortcomings of the U.S. federal income tax system?
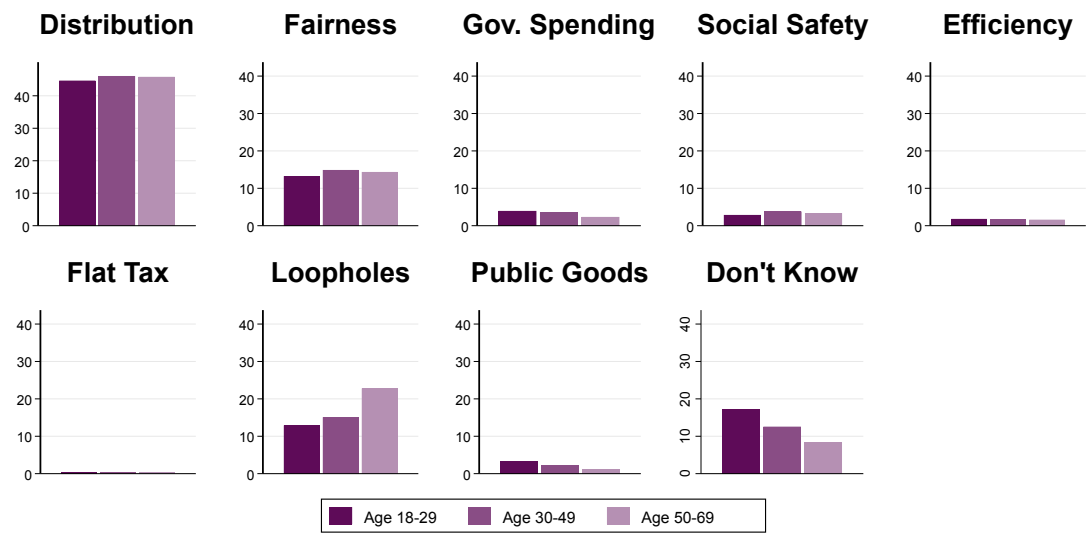

Notes: See the notes to Figure OA-8. 
Figure OA-11: Topic Distribution by Political Affiliation of the Estate Tax

(a) What are your Main Considerations about the U.S. federal estate tax system?
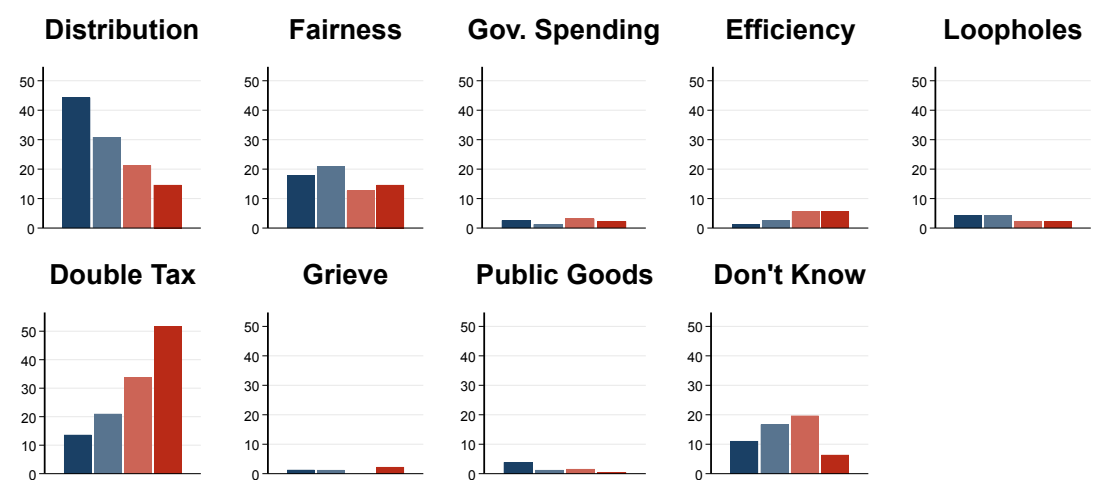

Grieve
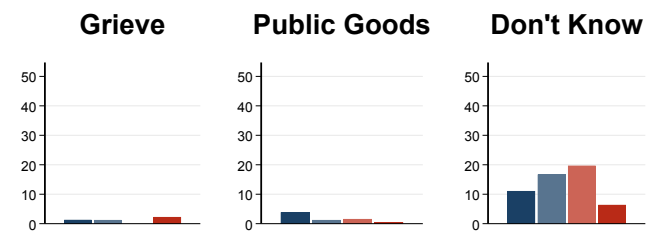

Clinton Liberal Clinton Moderate Trump Moderate

Trump Conservative

(B) What WOUld Be the GOAL OF A GOOD ESTAte taX System?
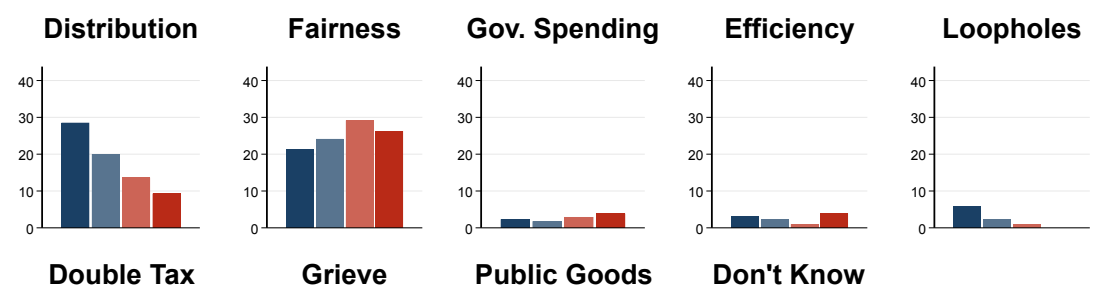

Grieve
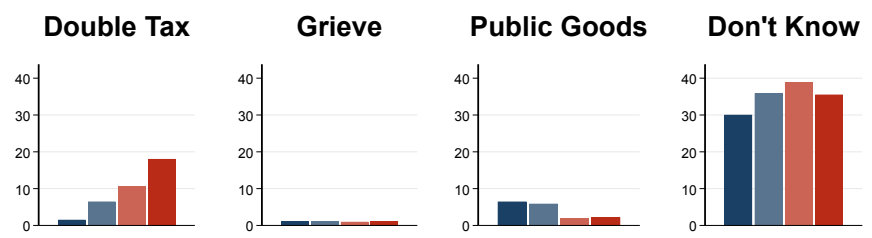

Clinton Liberal Clinton Moderate Trump Moderate

Trump Conservative

(c) What do you think are the Shortcomings of the U.S. FEDERAL ESTATE tax System?
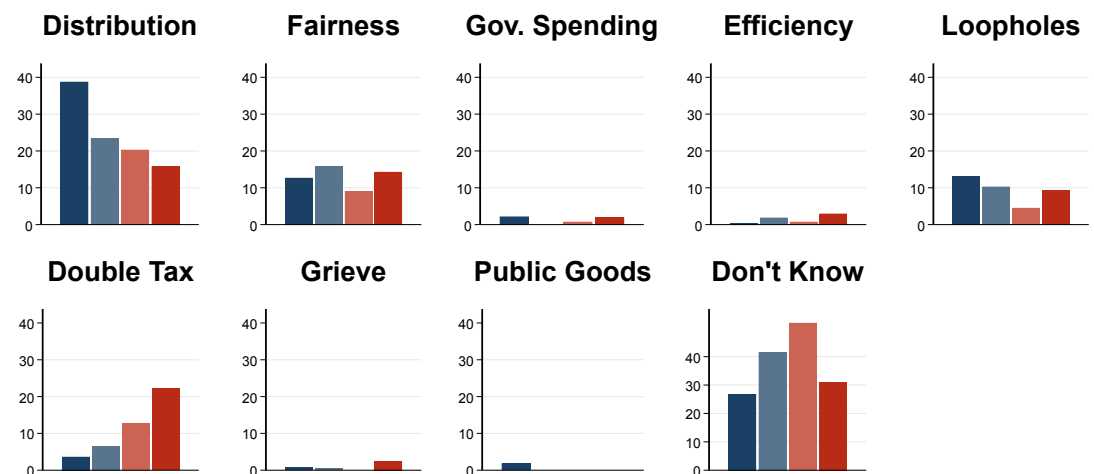

Public Goods
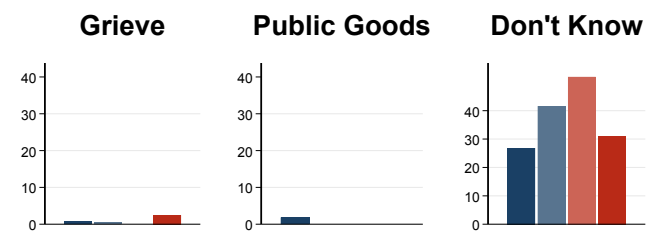

Clinton Liberal Clinton Moderate Trump Moderate

Trump Conservative

Notes: See the notes to Figure OA-8. 
Figure OA-12: Topic Distribution by Income Groups of the Estate Tax (a) What are your Main Considerations about the U.S. federal estate tax system?
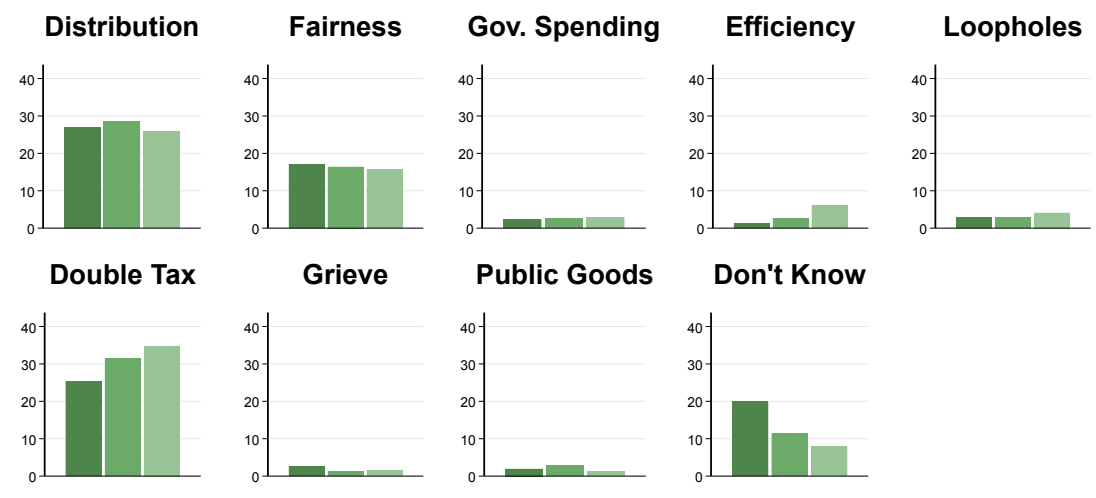

Public Goods
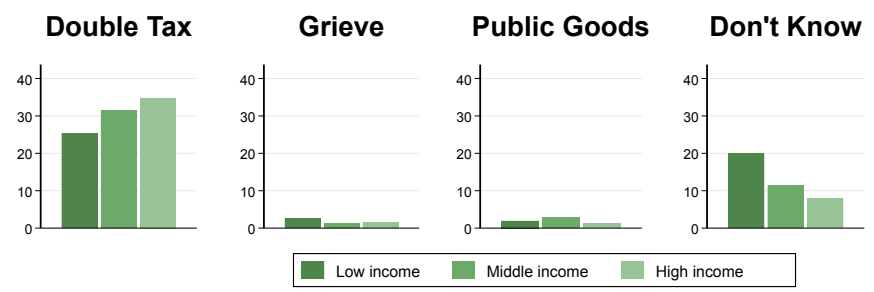

(B) What Would Be the GOAl of a Good estate tax System?
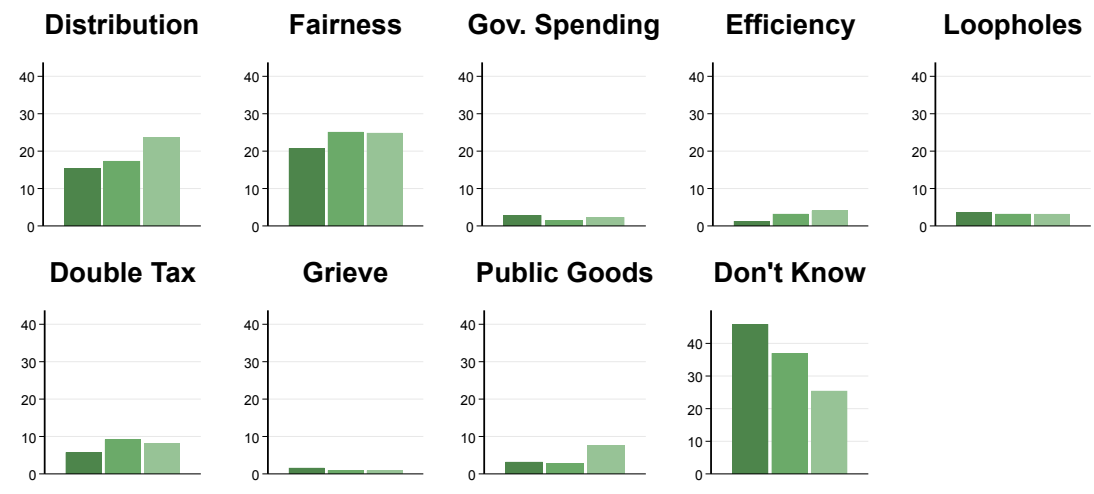

Public Goods
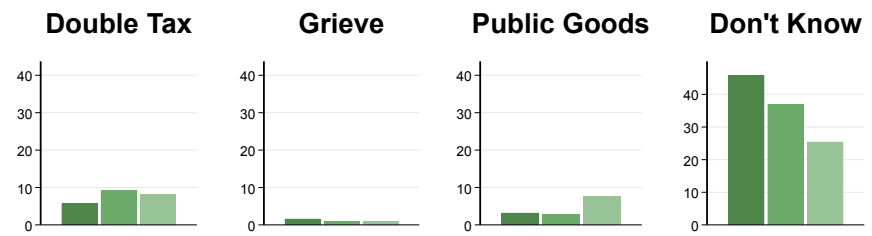

Low income Middle income High income

(c) What do you think are the Shortcomings of the U.S. federal estate tax system?
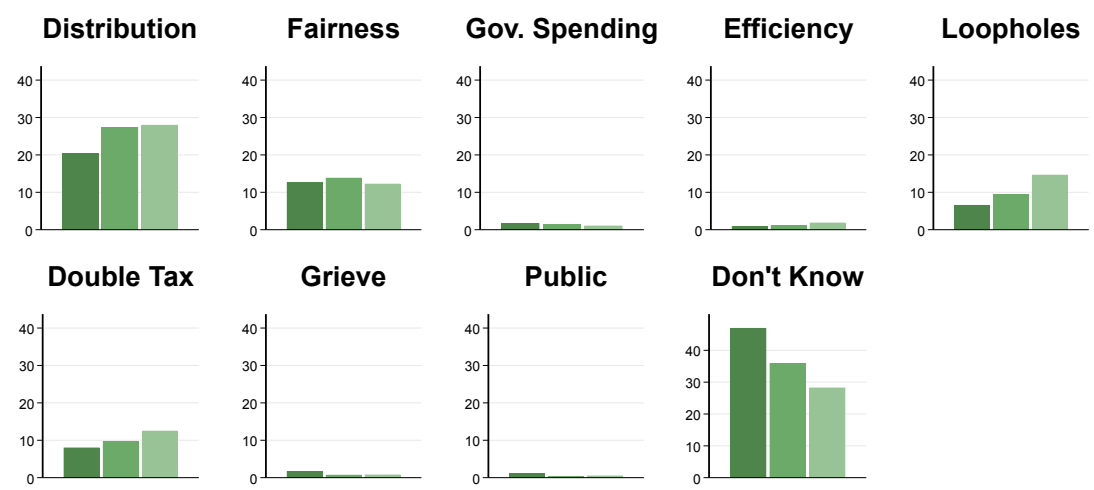

Low income Middle income High income

Notes: See the notes to Figure OA-9. 
Figure OA-13: Topic Distribution by Age Group of the Estate Tax (a) What are your Main Considerations about the U.S. federal estate tax system?
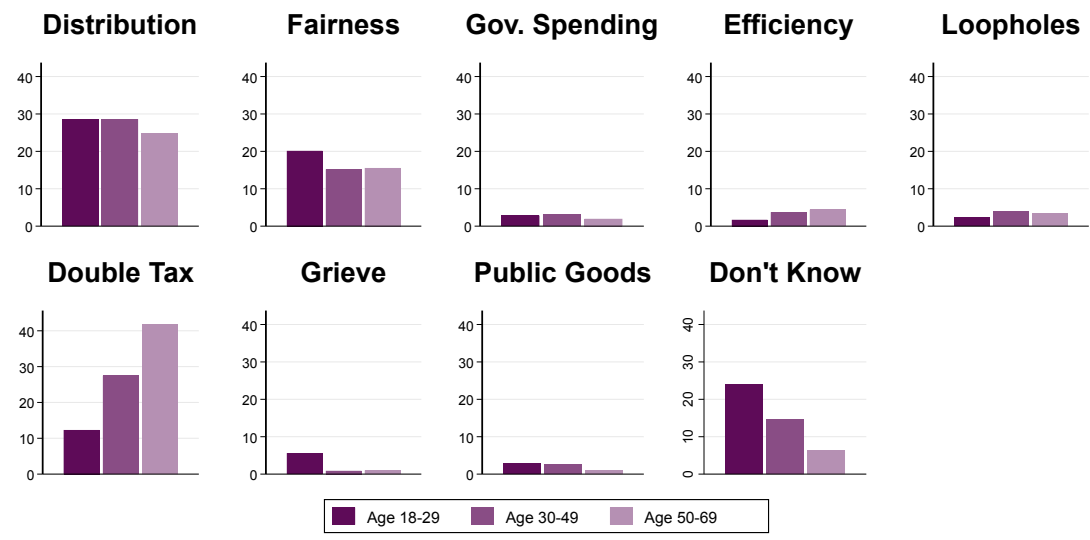

(B) What Would Be the GOAL of a Good Estate tax System?
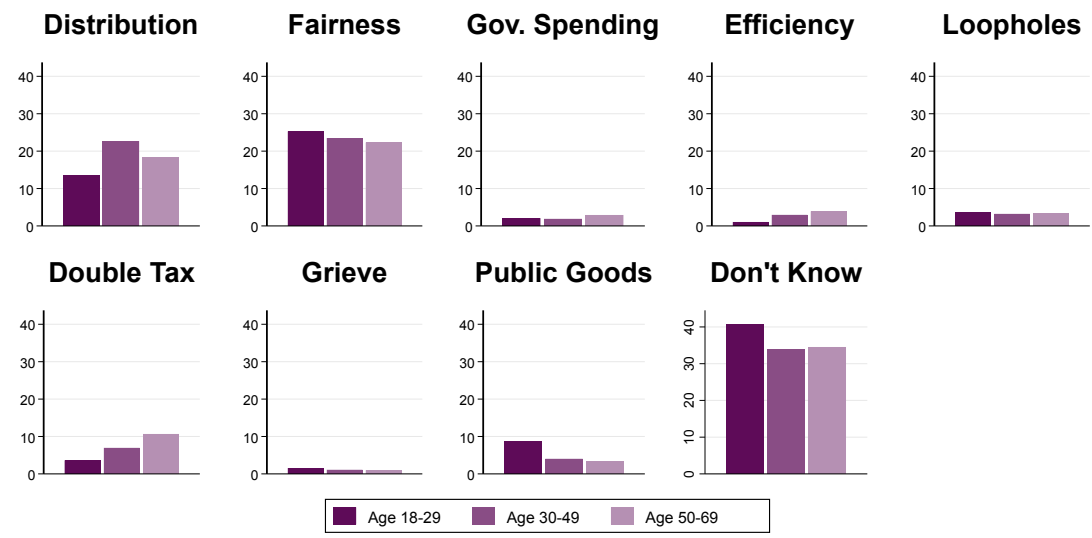

(c) What do you think are the Shortcomings of the U.S. federal estate tax system?
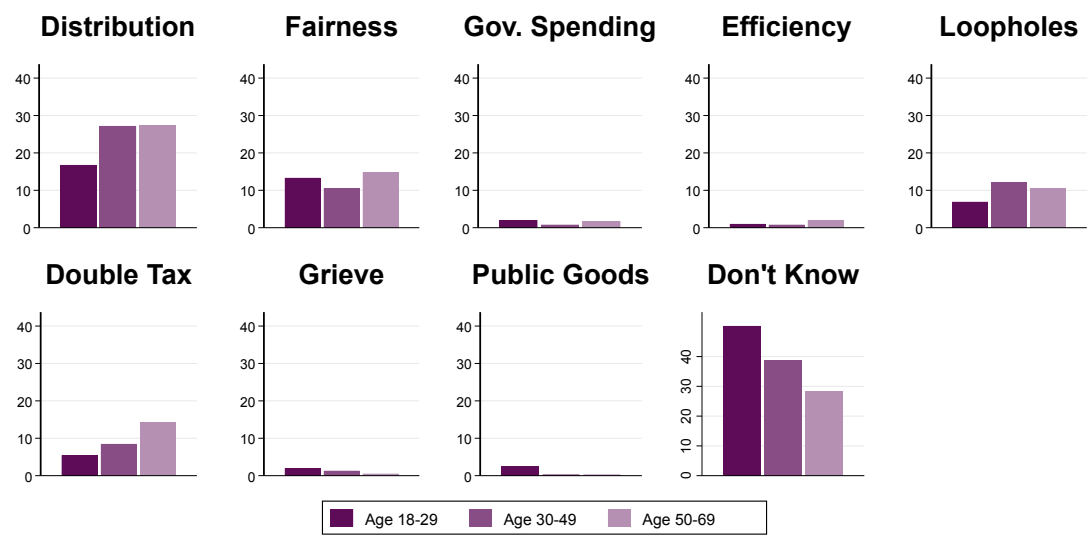

Notes: See the notes to Figure OA-8. 


\section{References}

Agrawal, A., W. Fu, and T. Menzies (2018). What is wrong with topic modeling? And how to fix it using search-based software engineering. Information and Software Technology 98, 74-88.

Baeza-Yates, R., B. Ribeiro-Neto, et al. (1999). Modern information retrieval, Volume 463. ACM press New York.

Banerjee, S., K. Ramanathan, and A. Gupta (2007). Clustering short texts using wikipedia. In Proceedings of the 30th annual international ACM SIGIR conference on Research and development in information retrieval, pp. 787-788.

Benoit, K., K. Watanabe, H. Wang, P. Nulty, A. Obeng, S. Müller, and A. Matsuo (2018). Quanteda: An r Package for the Quantitative Analysis of Textual Data. Journal of Open Source Software 3(30), 774.

Blei, D., A. Ng, M. Jordan, and J. Lafferty (2003, 02). Journal of machine learning research 3 (2003) 993-1022 submitted 2/02; published 1/03 latent dirichlet allocation.

Blei, D. M. and D. Jon (2007). Mcauliffe. supervised topic models. Advances in Neural Information Processing Systems 20, 121128.

Blei, D. M. and J. D. Lafferty (2006). Dynamic topic models. In Proceedings of the 23rd international conference on Machine learning, pp. 113-120.

Deerwester, S., S. T. Dumais, G. W. Furnas, T. K. Landauer, and R. Harshman (1990). Indexing by latent semantic analysis. Journal of the American society for information science 41(6), 391-407.

Flood, S., M. King, R. Rodgers, S. Ruggles, and J. R. Warren (2020). Integrated public use microdata series, current population survey: Version 8.0 [dataset]. Minneapolis, MN: IPUMS. https://doi.org/ 10.18128/D030.V8.0.

Gabrielatos, C. (2018, 02). Keyness analysis: Nature, metrics and techniques, pp. 225-258.

Gabrielatos, C. and A. Marchi (2011). Keyness: Matching metrics to definitions. In Theoreticalmethodological challenges in corpus approaches to discourse studies and some ways of addressing them.

Gallagher, R. J., K. Reing, D. Kale, and G. Ver Steeg (2017). Anchored correlation explanation: Topic modeling with minimal domain knowledge. Transactions of the Association for Computational Linguistics 5, 529-542.

Gallup (2019). Party Affiliation, In Depth: Topics A to Z. https://news.gallup.com/poll/15370/ party-affiliation.aspx.

Gentzkow, M. and J. M. Shapiro (2010). What Drives Media Slant? Evidence from US Daily Newspapers. Econometrica 78(1), 35-71.

Heimerl, F., S. Lohmann, S. Lange, and T. Ertl (2014). Word Cloud Explorer: Text Analytics Based on Word Clouds. In 2014 47th Hawaii International Conference on System Sciences, pp. 1833-1842.

Hofmann, T. (1999). Probabilistic latent semantic indexing. In Proceedings of the 22nd annual international ACM SIGIR conference on Research and development in information retrieval, pp. 50-57.

Kilgarriff, A. (2001). Comparing corpora. International journal of corpus linguistics 6(1), 97-133. Publisher: John Benjamins.

Leech, G. and R. Fallon (1992). Computer corpora-what do they tell us about culture. ICAME journal 16.

Leip, D. (2019). Election Results from the Associated Press. Atlas of U.S. Presidential Elections and David Wasserman of the Cook Political Report. https://uselectionatlas.org/RESULTS/.

Lu, B., M. Ott, C. Cardie, and B. K. Tsou (2011). Multi-aspect sentiment analysis with topic models. In 2011 IEEE 11th international conference on data mining workshops, pp. 81-88. IEEE.

Partington, A. (2014). Mind the gaps: The role of corpus linguistics in researching absences. International Journal of Corpus Linguistics 19(1), 118-146. 
Roberts, M. E., B. M. Stewart, D. Tingley, E. M. Airoldi, et al. (2013). The structural topic model and applied social science. In Advances in neural information processing systems workshop on topic models: computation, application, and evaluation, Volume 4, pp. 1-20. Harrahs and Harveys, Lake Tahoe.

Roberts, M. E., B. M. Stewart, D. Tingley, C. Lucas, J. Leder-Luis, S. K. Gadarian, B. Albertson, and D. G. Rand (2014). Structural topic models for open-ended survey responses. American Journal of Political Science 58(4), 1064-1082.

Salton, G. and M. J. McGill (1983). Introduction to modern information retrieval. mcgraw-hill.

Schönhofen, P. (2009). Identifying document topics using the wikipedia category network. Web Intelligence and Agent Systems: An International Journal 7(2), 195-207.

Stantcheva, S. (2021). Understanding tax policy: How do people reason? The Quarterly Journal of Economics $136(4), 2309-2369$.

Stubbs, M. (2010). Three concepts of keywords. Keyness in texts, 21-42.

Tang, J., Z. Meng, X. Nguyen, Q. Mei, and M. Zhang (2014, 22-24 Jun). Understanding the limiting factors of topic modeling via posterior contraction analysis. In E. P. Xing and T. Jebara (Eds.), Proceedings of the 31st International Conference on Machine Learning, Volume 32 of Proceedings of Machine Learning Research, Bejing, China, pp. 190-198. PMLR.

Taylor, C. (2013). Searching for similarity using corpus-assisted discourse studies. Corpora 8(1), 81-113.

Watanabe, K. (2018a). Conspiracist propaganda: How russia promotes anti-establishment sentiment online. In ECPR General Conference, Hamburg.

Watanabe, K. (2018b, March). Newsmap: A semi-supervised approach to geographical news classification. Digital Journalism 6(3), 294-309.

Watanabe, K. and Y. Zhou (2020). Theory-driven analysis of large corpora: Semisupervised topic classification of the un speeches. Social Science Computer Review, 0894439320907027. 